\title{
Globalización y senderos nacionales de desarrollo: algunos hechos estilizados para reflexionar sobre el caso argentino
}

\author{
Lorenzo Cassini, Gustavo García Zanotti y Martín Schorr
}

\section{Resumen}

En este trabajo se abordan de modo estilizado los senderos productivos y el desempeño socioeconómico de un conjunto de países durante las últimas décadas, con el fin de analizar el caso argentino mediante un enfoque comparativo. Para ello, se seleccionaron nueve países (Argentina, Australia, Brasil, Chile, China, India, México, Noruega y República de Corea) y se realizó un análisis a largo plazo por medio de la elaboración de indicadores que sintetizan los senderos productivos y el desempeño de estas economías. Se concluye que, durante este período, destacan dos grandes tipos de senderos productivos. Por un lado, uno basado en ventajas dinámicas focalizadas en bienes de alto contenido tecnológico, que da como resultado un desempeño favorable. Por otro lado, un sendero productivo basado en ventajas estáticas, como mano de obra barata o abundancia de recursos naturales, que conduce a desempeño disímiles.

\section{Palabras clave}

Globalización, desarrollo económico, desarrollo social, política de desarrollo, industrialización, cambio tecnológico, capacidad de ciencia y tecnología, estrategias del desarrollo, estudios de casos, Noruega, Australia, México, Brasil, Argentina, Chile, China, India, República de Corea

\section{Clasificación JEL}

O57, 014,033

\section{Autores}

Lorenzo Cassini es becario doctoral del Instituto de Altos Estudios Sociales (IDAES), dependiente de la Universidad Nacional de San Martín (UNSAM), Argentina. Correo electrónico: Icassini@unsam.edu.ar.

Gustavo García Zanotti es becario posdoctoral en el Consejo Nacional de Investigaciones Científicas y Técnicas (CONICET), Argentina. Correo electrónico: gustavo.d.garcia89@gmail.com.

Martín Schorr es investigador del CONICET e investigador y profesor en el IDAES, Argentina. Correo electrónico: schorr.mar@gmail.com. 


\section{Introducción}

En términos generales, el proceso de desarrollo económico comprende una transformación estructural que abarca dos dimensiones. Por un lado, una modificación del patrón de especialización sectorial, en el cual ganan participación actividades de mayor productividad y dinamismo tecnológico. Por otro lado, un aumento de la productividad y mejoras tecnológicas, que incluyen el desarrollo de los encadenamientos productivos de mayor valor agregado. Los países con éxito en su consolidación siguieron distintas estrategias en lo que respecta tanto a su patrón de especialización como a la política implementada para impulsar el cambio estructural. Al mismo tiempo, otros países no llevaron a cabo el cambio estructural necesario y se distinguen de los países exitosos tanto por su patrón de especialización como por las políticas impulsadas. El objetivo de este trabajo es reflexionar sobre posibles trayectorias para el desarrollo argentino a partir del análisis estilizado de los caminos seguidos por países que se pueden considerar "exitosos" y "no exitosos".

Para ello, se analizan nueve países - Argentina, Australia, Brasil, Chile, China, India, México, Noruega y República de Corea- que se consideran representativos de diversas estrategias de desarrollo. El horizonte temporal escogido para esta investigación abarca los años comprendidos entre 1963 y 2014. Se caracterizan las trayectorias de cada país considerando el cambio estructural, los instrumentos utilizados y las políticas industriales para analizar el comportamiento técnico-productivo y el rol de los diversos actores económicos. Este análisis a largo plazo nos permitirá identificar senderos productivos, así como el desempeño, medido por el nivel de vida y el grado de incidencia comercial, que posibilitó cada trayectoria ${ }^{1}$.

La inclusión de los principales países latinoamericanos obedece al hecho de que sus estructuras productivas presentan algunas características en común: una elevada heterogeneidad estructural y una especialización centrada principalmente en sus respectivas ventajas comparativas. Por otro lado, se incorporan a la muestra Australia y Noruega, dado que estos dos países cuentan con una gran dotación de recursos naturales per cápita, los que parte de los trabajos en la materia proponen como modelo para los países latinoamericanos, pensando en una estrategia de desarrollo basada en el escalonamiento tecnológico a partir de los recursos naturales (Pérez, 2010). Por último, la selección de China, la India y la República de Corea se justifica por su crecimiento vertiginoso durante las últimas décadas.

Se entiende que existe poca bibliografía en lo que respecta a este tema. Diferentes estudios empíricos han encontrado una relación significativa entre el perfil de especialización comercial de un país y su tasa de crecimiento (Hausmann, Hwang y Rodrik, 2007; Rodrik, 2006; Dalum, Laursen y Verspagen, 1999; Lavopa, 2015), mientras que otros han puesto su atención en descomponer cuánto del crecimiento económico de un país se debe al cambio en su estructura productiva y cuánto a aumentos de la productividad intrasectorial por medio de técnicas de análisis de tipo diferencial-estructural (shift-share) (Castaldi, 2009; De Vries y otros, 2011; Verspagen, 2000; Wang y Szirmai, 2008). Sin embargo, estos trabajos no distinguen entre las trayectorias seguidas a largo plazo por cada país ni entre las políticas públicas y los actores involucrados en cada proceso. Por otra parte, existen estudios que abordan el devenir productivo de los casos nacionales, de cuyos aportes nos valdremos a lo largo de este trabajo, pero se hallan pocos estudios comparativos con una perspectiva a tan largo plazo en las dimensiones analíticas que se toman en consideración (CEPAL, 2007; Cimoli y otros, 2005; Schteingart, 2017).

\footnotetext{
1 Por una limitación de espacio, este artículo se centra en los principales hechos estilizados que distinguen las trayectorias nacionales en una perspectiva a largo plazo y en función del recorte analítico propuesto. Ello no implica desconocer que existen una multiplicidad de variables que han intervenido de modo particular en cada espacio nacional para dar cuenta de los diferentes senderos transitados (régimen macroeconómico, instrumentos de fomento priorizados, trayectoria histórica, contexto institucional o coaliciones sociales, entre otras). En Cassini, García Zanotti y Schorr (2017) y la bibliografía que allí se sistematiza, puede consultarse un análisis integral de los diversos casos que aquí se abordan.
} 
El trabajo se encuentra estructurado de la siguiente forma: en la primera sección, se exponen las consideraciones metodológicas para elaborar las diversas variables que representan las distintas trayectorias y se propone una taxonomía para estas; en la segunda sección, se tratan las distintas trayectorias de los países seleccionados a partir de la clasificación elaborada en la primera sección y, sobre esa base, se cierra el trabajo con una breve reflexión final sobre las alternativas para el desarrollo en la Argentina.

\section{Cuestiones metodológicas}

\section{Capacidades tecnológicas y contenido tecnológico neto}

Para caracterizar el sendero de desarrollo seguido por cada país, se utilizan dos dimensiones de análisis: una vinculada a la especialización productiva - el contenido tecnológico neto - y otra, al progreso tecnológico - las capacidades tecnológicas -. Por un lado, las capacidades de generación y aprendizaje tecnológico (aquí denominadas "capacidades tecnológicas") resultan fundamentales en el proceso de desarrollo económico para mejorar la competitividad sistémica y agregar valor a la producción (Marín, 2016; Pérez, 2001; Lugones, Suárez y Gregorini, 2007). Por otro lado, la especialización productiva en bienes de alto contenido tecnológico impulsa el avance técnico y dinamiza la generación de riqueza (Araujo y Lima, 2007; Cimoli, Porcile y Rovira, 2010; Dosi, Pavitt y Soete, 1993).

La especialización tecnoproductiva se infiere en este trabajo a partir de la balanza comercial, es decir, analizando en qué medida el país se especializa en la producción de bienes con una mayor incorporación de tecnología. Este indicador se sintetiza en el contenido tecnológico neto², que, al considerar tanto importaciones como exportaciones, permite aproximarse a la incorporación de contenido tecnológico netamente nacional, lo cual es importante para evaluar la trayectoria seguida por países con mucho peso de sectores maquiladores o ensambladores en su canasta exportadora. El indicador de contenido tecnológico neto puede asumir valores teóricos que van desde -100, cuando un país importa únicamente bienes de muy alta tecnología sin exportar bienes tecnológicos, hasta 100, si un país exporta solo bienes de muy alta tecnología, sin importar bienes tecnológicos. En ese marco, un país será exportador neto de bienes tecnológicos ${ }^{3}$ si su contenido tecnológico neto se encuentra por encima de la línea guía horizontal (es decir, por encima de cero o del nivel neutro).

\footnotetext{
2 Para calcular este indicador, se toma el gasto en investigación y desarrollo (l+D) privado como porcentaje del valor agregado (intensidad tecnológica o contenido tecnológico) para cada una de las 34 ramas de actividad (a 2, 3 o 4 dígitos, según la disponibilidad de datos en OECD.Stat [en línea] https://stats. oecd.org/) y se lo normaliza tomando el valor más alto como 100. Para cada país, se pondera la intensidad tecnológica normalizada por la participación de cada rama en la canasta exportadora del país y se genera un índice de contenido tecnológico de las exportaciones de ese país. Lo mismo se hace con las importaciones, y el índice de contenido tecnológico de la balanza comercial (CTN) resulta de la diferencia entre el índice de contenido tecnológico de las exportaciones y el de las importaciones, pudiendo asumir valores de entre 100 y - 100. La forma de calcular el CTN para un país determinado es la expresada por la siguiente ecuación: $C T N=\sum_{i=1}^{34} I+D_{i}{ }^{*} s_{i}^{e x p}-\sum_{i=1}^{34} I+D_{i}{ }^{*} s_{i}^{i m p}$, donde $I+D_{i}$ es el gasto en I+D privado como porcentaje del valor agregado (normalizado) en la rama de actividad $i$ y $S_{i}^{\text {exp } / i m p}$ es la participación de la rama de actividad $i$ en la canasta de importaciones o exportaciones del país. Cabe señalar que este indicador compara la composición de las exportaciones e importaciones de acuerdo con su contenido tecnológico, pero no tiene en cuenta sus montos totales. Además, se clasifican las exportaciones e importaciones de cada país de acuerdo con la taxonomía por contenido tecnológico propuesta por la Organización de Cooperación y Desarrollo Económicos (OCDE) para complementar la caracterización de los senderos de desarrollo. Finalmente, se excluyen los servicios tanto del indicador como de la clasificación, por no estar incluidos en la clasificación de la OCDE (véase [en línea] https://www.oecd.org/sti/ ind/48350231.pdf).

3 No obstante, esto no quiere decir que dicho país necesariamente genere tecnología. Para ello debería disponer de niveles elevados de capacidades tecnológicas.
} 
Las capacidades tecnológicas ${ }^{4}$ se sintetizaron por medio de un número índice que refleja la evolución de las patentes de tecnología per cápita de cada país ${ }^{5}$, así como el porcentaje de gasto en innovación y desarrollo (I+D) sobre el producto interno bruto (PIB) correspondiente 6 . El número índice normaliza las capacidades tecnológicas y varía entre 0 y $1^{7}$. Se acerca a 1 si el país cuenta con un nivel elevado de capacidades tecnológicas. Además, se agrega una línea guía en el valor 0,35 de las capacidades tecnológicas, que corresponde a la mediana de dichas capacidades en los países seleccionados. Este registro permite diferenciar a los países de capacidades tecnológicas bajas de los de capacidades tecnológicas altas.

Sobre la base de la utilización de los dos indicadores mencionados, pueden distinguirse distintos tipos de senderos (véase el gráfico 1). Los países que se encuentran actualmente en el cuadrante sudoeste poseen un perfil de especialización e inserción internacional con una presencia destacada de bienes primarios y dificultades en lo atinente a la incorporación de tecnología. Se trata de los países "reprimarizados con bajas capacidades tecnológicas".

El cuadrante noroeste corresponde a países que utilizan la maquila como estrategia de desarrollo. De ahí que en este estudio sean catalogados como países "industrializados con bajas capacidades tecnológicas".

Por otra parte, en el cuadrante sudeste se ubican aquellas naciones que han desplegado una estrategia basada en su dotación de recursos naturales, pero con un importante agregado local de valor y conocimiento tecnológico. Estos son los países caracterizados como "primarizados con capacidades tecnológicas".

Finalmente, el cuadrante noreste corresponde a los países con una estrategia de industrialización que se inserta en los eslabones de mayor componente tecnológico de las cadenas de valor globales. Allí destacan los países que se encontraban en un primer momento en el cuadrante sudoeste y siguieron un sendero de industrialización hasta alcanzar el cuadrante noreste. Dicho sendero se denominará "industrialización con capacidades tecnológicas recientes".

4 A continuación, se describen los pasos seguidos para el cálculo de las capacidades tecnológicas (CT): i) se elaboró un índice de patentes $(\mathrm{IP})$ de la siguiente manera $I P=\left[\frac{\log \left(\text { P per cápita }_{i t}+1\right)}{\log \left(\text { P per cápita }_{\text {taiwan }}+1\right)}\right]$, donde P per cápita son las patentes per cápita otorgadas; ii) a continuación, se elaboró un índice de inversión en I+D (II+D) de la siguiente manera: $I I+D=\left[\frac{\log \left(\% I+D_{i t}+1\right)}{\log \left(\% I+D_{\text {israel }}+1\right)}\right]$, donde $\% 1+D$ es el porcentaje de inversión en I+D sobre el PIB de cada país, y iii) por último, se calcularon las CT como $C T=\left[I P_{i} * I I+D_{i t}\right]^{1 / 2}$.

5 Si bien las patentes de tecnología no se consideran un fenómeno innovador, se toman como indicador indirecto. Por otra parte, no se puede ignorar el hecho de que, en muchos países periféricos, las patentes son reválidas locales de patentes de empresas transnacionales con escasos (o nulos) esfuerzos tecnológicos domésticos.

6 Para elaborar el número índice, se siguió a Schteingart (2014). Las patentes aprobadas se extrajeron de la Oficina de Marcas y Patentes de los Estados Unidos [en línea] https://www.uspto.gov/web/offices/ac/ido/oeip/taf/cst_utlh.htm, mientras que la evolución de la población se basó en las series del Banco Mundial [en línea] https://datos.bancomundial.org/indicador/SP.POP. TOTL . Por su parte, la evolución del porcentaje de I+D sobre PBI fue extraída de las siguientes fuentes: OCDE Data [en línea] https://data.oecd.org/rd/gross-domestic-spending-on-r-d.htm, Fundación Nacional de Ciencias [en línea] https://www.nsf.gov/ statistics/2018/nsb20181/report/sections/research-and-development-u-s-trends-and-international-comparisons/recent-trendsin-u-s-r-d-performance (Estados Unidos), Red Regional de Indicadores de Ciencia y Tecnología (RICYT) [en línea] http://www. ricyt.org/category/indicadores/ (América Latina), Organización de las Naciones Unidas para la Educación, la Ciencia y la Cultura (UNESCO) [en línea] http://data.uis.unesco.org/index.aspx?queryid=74, y Banco Mundial [en línea] https://datos. bancomundial. org/indicador/GB.XPD.RSDV.GD.ZS.

7 Para transformarlos en número índice se consideró el nivel de patentes per cápita de la Provincia China de Taiwán en 2014 y el porcentaje de I+D de Israel en el mismo año. Es decir, el valor de las capacidades tecnológicas se situará entre 0 y 1 dependiendo de su similitud con el de dichos países. 


\section{Gráfico 1}

Senderos productivos: contenido tecnológico neto de la balanza comercial y capacidades tecnológicas

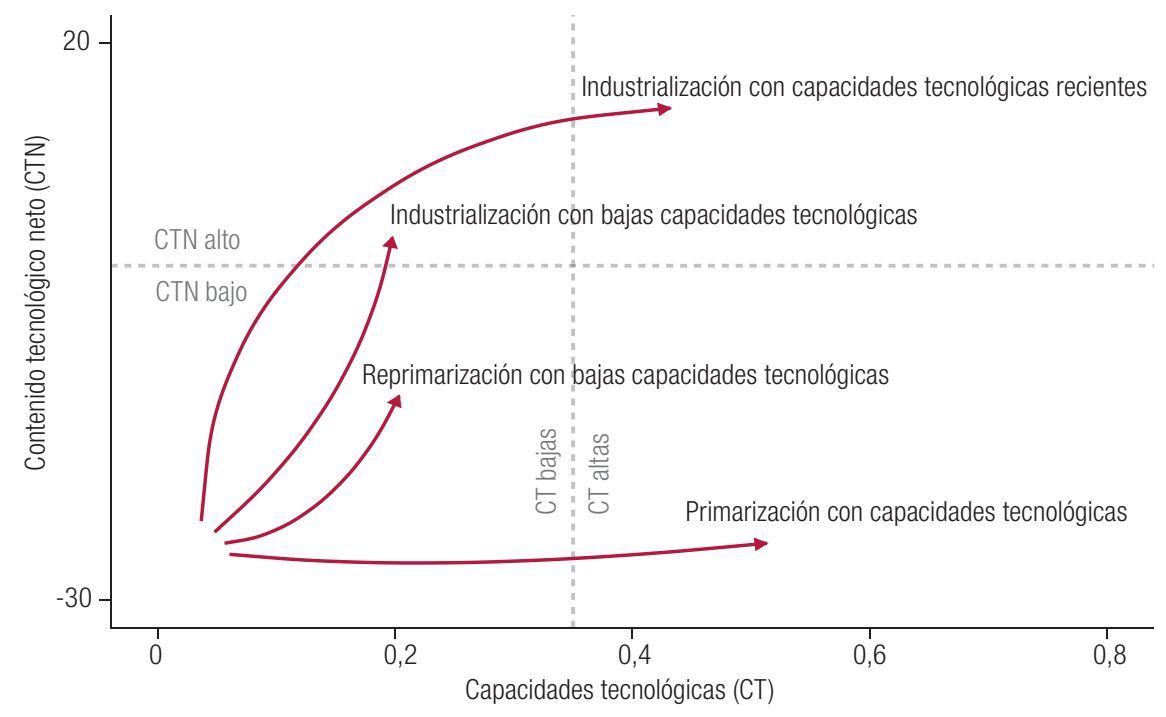

Fuente: Elaboración propia.

\section{Incidencia comercial y calidad de vida}

La trayectoria seguida por cada país en el transcurso del período estudiado también será caracterizada a partir de otras dos dimensiones de análisis referidas al desempeño de estas economías. La primera de ellas indica en qué medida los países se especializan en bienes cuya participación en el comercio mundial se encuentra en aumento. Se la considera una variable de desempeño porque es parcialmente consecuencia del contenido tecnológico de la canasta exportadora al que nos referimos en la sección anterior y porque el aumento sostenido de las exportaciones sienta las bases para relajar la restricción externa al crecimiento (Thirlwall y McCombie, 2004; Cimoli, Porcile, y Rovira, 2010). Esta dimensión se representa empíricamente mediante un índice denominado "canasta de participación creciente", que hace referencia a la medida en que los productos de la canasta exportadora de un país determinado tienen una participación cada vez mayor en el comercio mundial ${ }^{8}$. Este índice puede adoptar valores teóricos de entre - 0,73 y 5,79 si el país se especializa completamente en la exportación del bien que más participación perdió o más participación ganó en las exportaciones mundiales, respectivamente. En los ejercicios analíticos que siguen, si el índice de canasta de participación creciente se encuentra a la derecha de la línea guía (esto es, es mayor que cero o se encuentra por encima del nivel neutro), significa que la canasta exportadora del país en cuestión cuenta con una mayor ponderación en el comercio internacional.

Asimismo, siguiendo la propuesta metodológica de Bértola, Hernández y Siniscalchi (2012), se elaboró un índice de desarrollo humano (IDH), que constituye un indicador indirecto de la calidad

\footnotetext{
8 Para calcular este índice, primero se estima el aumento de la participación de cada rubro (a tres dígitos) en el comercio mundial, comparando el promedio de los períodos 1964-1974 y 2004-2014. Luego, para obtener el índice correspondiente a cada país, se pondera el aumento de la participación de cada rubro por la participación que cada rubro tiene en la canasta exportadora del país. La fórmula para el cálculo del índice para un país determinado es la siguiente: $C P C=\sum_{i}^{n} \Delta s_{i}^{\exp m u n} * s_{i}^{\exp }$, donde $\Delta s_{i}^{\text {expmun }}$ es el aumento de la participación de cada rubro en el comercio mundial, $s_{i}^{\text {exp }}$ es la participación de ese rubro en la canasta exportadora del país y $n$ es la cantidad de rubros.
} 
de vida promedio de la población de cada país 9 . Un país se acercará a las condiciones óptimas si su PIB per cápita, nivel educativo y nivel de salud aumentan ${ }^{10}$. Cuando el IDH se acerca a 1, se asume que la economía está alcanzando altos niveles de desarrollo humano. Además, se agrega una línea guía en el valor 0,6, que corresponde a la mediana del IDH de los países seleccionados en la actualidad. Dicho nivel diferencia a los países con desarrollo humano bajo de los países con desarrollo humano alto. Los países que se encuentran próximos a dicho nivel son considerados de desarrollo humano medio.

En el gráfico 2, se muestran diversos tipos de desempeños. Los países que actualmente se encuentran próximos al cuadrante noroeste, se consideran de desarrollo humano medio sin incidencia comercial.

\section{Gráfico 2}

Trayectoria del desempeño: canasta de participación creciente e índice de desarrollo humano

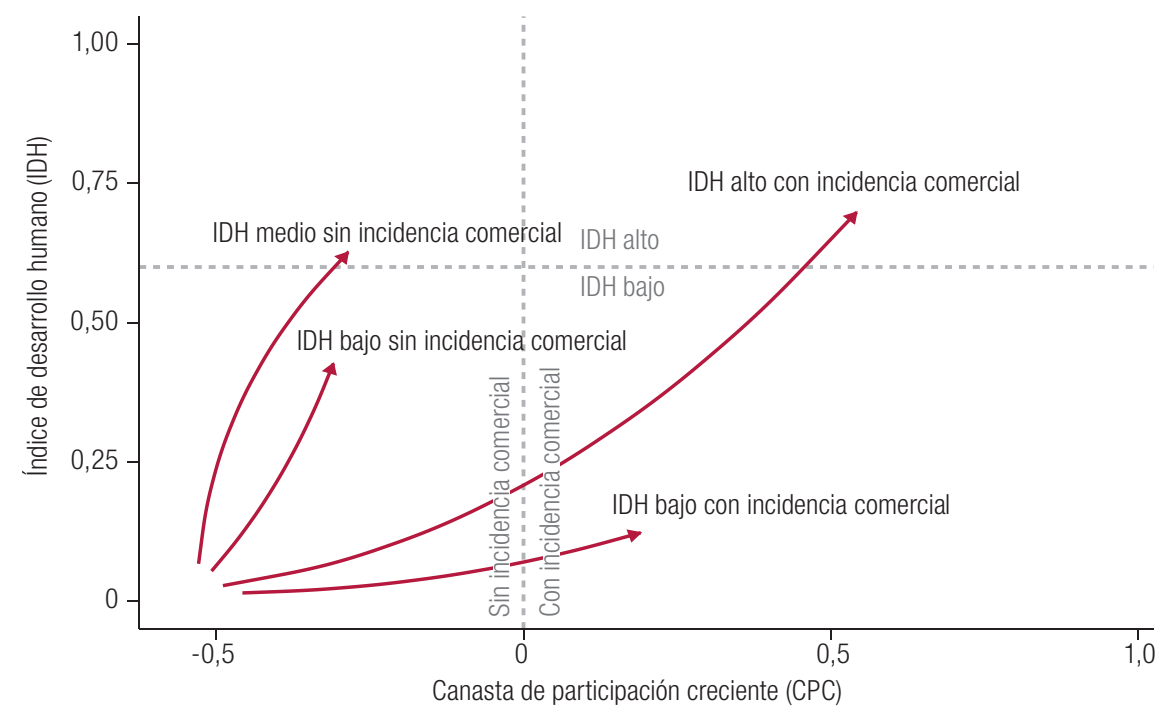

Fuente: Elaboración propia.

Los países que se encuentran en el cuadrante noreste se consideran de desarrollo humano alto con incidencia comercial. Dicha categoría puede variar si el país anteriormente se encontraba en el cuadrante sudoeste. En caso de tratarse de un gran ascenso, se lo podría considerar como de desarrollo humano alto con incidencia comercial creciente.

Los países que se encuentran en el cuadrante sudoeste se clasifican como naciones de desarrollo humano bajo sin incidencia comercial. En tanto, los países del cuadrante sudeste pueden considerarse de desarrollo humano bajo con incidencia comercial.

\footnotetext{
9 La fórmula para el cálculo del IDH es la siguiente: $I D H=\left[\left(\frac{P_{I B} \text { per cápita }}{40000-100}\right) *\left(\frac{P A E_{i t}}{16}\right) *\left(\frac{E V_{i t}-20}{85-20}\right)\right]^{1 / 3}$, donde PIB per cápita ${ }_{i t}$ es el $\mathrm{PIB}$ en paridad de poder adquisitivo per cápita, $P A E_{i t}$ es el promedio de años de escolarización y $E V_{i t}$ es la esperanza de vida.

10 Para elaborar el IDH, se siguió la metodología de Bértola, Hernández y Siniscalchi (2012). Dicho índice es similar al elaborado por el Programa de las Naciones Unidas para el Desarrollo (PNUD, 2015), solo que no se corrige por desigualdad. Se optó por elaborar un índice nuevo, ya que el del PNUD no abarca la dimensión temporal estudiada. En lo que respecta a las variables para la elaboración del índice, el PIB a paridad de poder adquisitivo fue extraído de la Maddison Project Database (Bolt y van Zanden, 2014), el nivel educativo se calculó a través de la cantidad de años promedio de escolarización, sobre la base de los datos de Barro y Lee (2013), y el indicador de nivel de salud se basó en los datos de la esperanza de vida al nacer del Banco Mundial [en línea] https://datos.bancomundial.org/indicador/SP.DYN.LEOO.IN.
} 


\section{Los senderos nacionales de desarrollo: una mirada a largo plazo}

\section{Países industrializados}

\section{a) Países con capacidades tecnológicas}

De acuerdo con los criterios metodológicos asumidos, en esta tipología quedan incluidos tanto la República de Corea como China, países que - por supuesto, con sus particularidades - se han caracterizado por un elevado nivel de intervención estatal en lo que se refiere a la modernización tecnológica y la ampliación y la diversificación de la estructura productiva impulsadas por la exportación de bienes.

En la República de Corea, el Estado se constituyó como entidad disciplinaria en materia de trabajo y capital; en este último caso, al castigar los malos resultados y premiar el buen desempeño de las empresas promovidas, pero, al mismo tiempo, enraizarse con autonomía relativa en los negocios por medio de una burocracia meritocrática (Hikino y Amsden, 1995; Chang, 2009). Entre las políticas seguidas para alcanzar tal fin, se encuentran los créditos bancarios, las exenciones tributarias, las cuotas de importación, los subsidios, el proteccionismo arancelario y las tarifas preferenciales, entre otras. De esta forma, el Estado alentó la creación de conglomerados diversificados propios denominados chaebol, con el fin de desarrollar las industrias definidas como prioritarias y estratégicas (Amsden, 1992 y 1993).

Por su parte, el sendero de China de reformas hacia un "socialismo de mercado" primero y, posteriormente, como potencia capitalista, comenzó en 1978 por medio de la eliminación de las comunas rurales y las restricciones a la comercialización de productos agrícolas por parte de las familias rurales.

El Estado chino no centró su política económica en orientar su desarrollo hacia el crecimiento de las exportaciones sino hasta 1992, después de que el Partido Comunista viera el éxito de las zonas económicas exclusivas (ZEE) ${ }^{11}$. Este proceso se acentuó en 2001, cuando China ingresó en la Organización Mundial del Comercio (OMC) (Moncaut y Vázquez, 2017). En tanto, el Estado ha participado íntegramente de la producción. Por un lado, a través de las empresas estatales, cuya presencia es prominente en los sectores del petróleo, la minería y la industria pesada (química y siderúrgica) y en el ámbito de los servicios públicos, y, por otro lado, a través de la creación de asociaciones (joint ventures) (Gereffi, 2010).

El sendero de desarrollo seguido por la República de Corea y China en las últimas décadas les ha permitido ganar en complejidad productiva. Como se desprende de la información volcada en el gráfico 3, ambos países se posicionan actualmente en el cuadrante noreste del sendero productivo. Sin embargo, ambos se encontraban en el cuadrante sudoeste en la década de 1960.

\footnotetext{
${ }^{11}$ Las ZEE se crearon en la década de 1980 con el fin de estimular la instalación de fábricas destinadas a la exportación gracias a las exenciones impositivas.
} 


\section{Gráfico 3}

China y República de Corea: contenido tecnológico neto de la balanza comercial y capacidades tecnológicas (sendero productivo) de dos países de industrialización reciente con capacidades tecnológicas recientes, 1963-2014
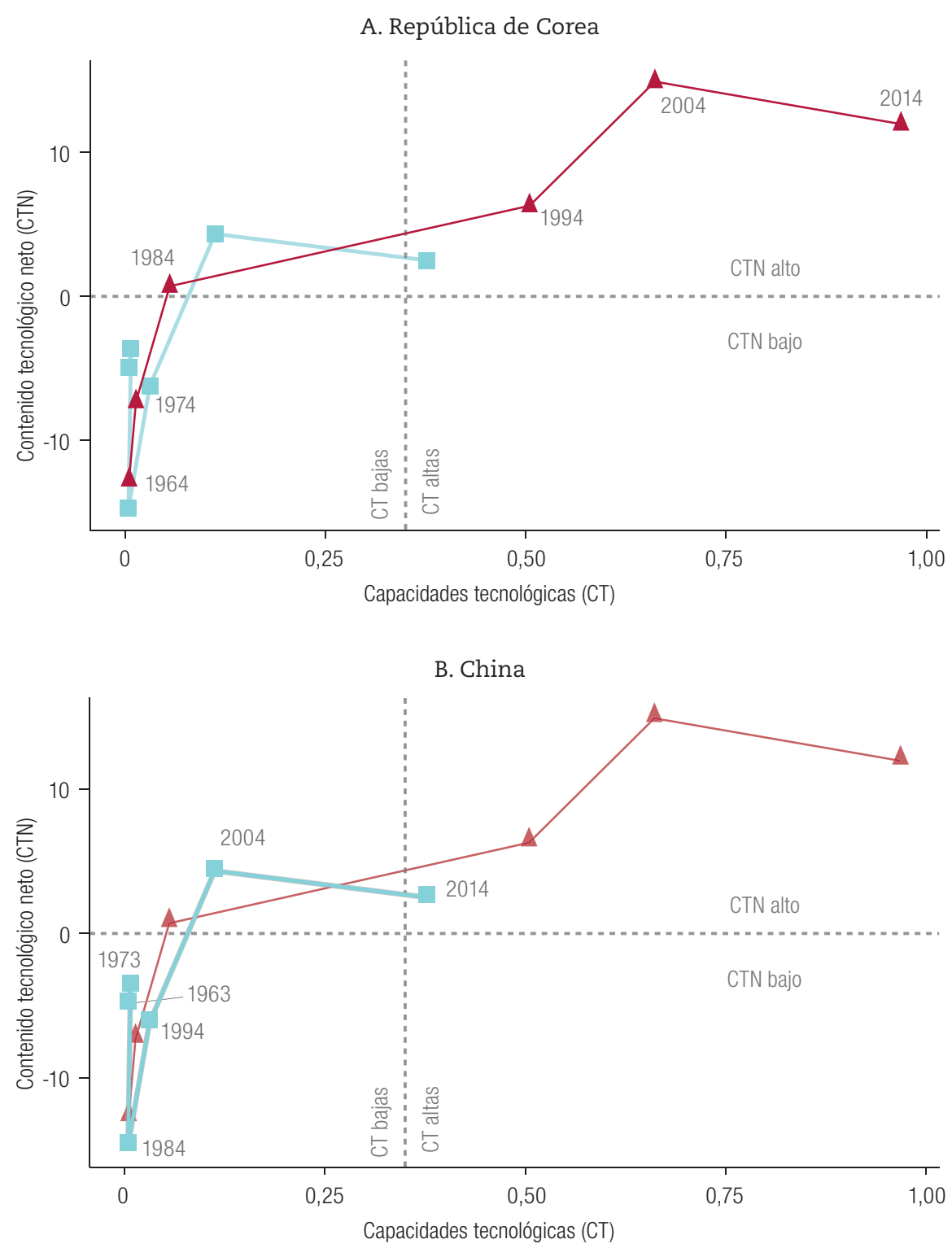

Fuente: Elaboración propia, sobre la base de Naciones Unidas, "UN Comtrade Database”, 2017 [base de datos en línea] https:// comtrade.un.org/; Oficina de Patentes y Marcas de los Estados Unidos, "Extended year set - patent counts by country, state, and year utility patents (December 2015)", 2020 [en línea] https://www.uspto.gov/web/offices/ac/ido/oeip/taf/ cst_utlh.htm; Organización de Cooperación y Desarrollo Económicos (OCDE), "Gross domestic spending on R\&D", 2020 [base de datos en línea] https://data.oecd.org/rd/gross-domestic-spending-on-r-d.htm; Fundación Nacional de Ciencias, "Recent trends in U.S. R\&D performance", 2018 [base de datos en línea] https://www.nsf.gov/statistics/2018/ nsb20181/report/sections/research-and-development-u-s-trends-and-international-comparisons/recent-trends-in-u-sr-d-performance; Red de Indicadores de Ciencia y Tecnología (RICYT), "Comparativos", 2020 [base de datos en línea] http://www.ricyt.org/category/indicadores/; Organización de las Naciones Unidas para la Educación, la Ciencia y la Cultura (UNESCO), "Science, technology and innovation: Gross Domestic Expenditure on R\&D (GERD), GERD as a percentage of GDP, GERD per capita and GERD per researcher", 2020 [base de datos en línea] http://data.uis.unesco. org/index.aspx?queryid=74, y Banco Mundial, "Gasto en investigación y desarrollo (\% del PIB)", 2020 [base de datos en línea] https://datos.bancomundial.org/indicador/GB.XPD.RSDV.GD.ZS. 
La participación de las exportaciones de alta tecnología sobre el total de las ventas externas de China pasó del 2,0\% en 1974 al 28,4\% en 2014, mientras que las de tecnología media-alta se incrementaron de un 10,0\% a un 24,7\% en el mismo período. Cabe destacar que China se convirtió en un país importador de recursos naturales en el último decenio y medio, ya que el peso de las materias primas en sus importaciones pasó del 14\% a casi el 30\% entre 2000 y 2014. De acuerdo con los datos del gráfico 3, en el caso de la República de Corea, se observa un contenido tecnológico neto creciente a lo largo de toda la serie. El peso de las exportaciones de alta tecnología pasó del 1\% en 1963 a alrededor del 35\% en 2004 y, posteriormente, descendió al 24\% en 2014. Las importaciones de alta tecnología, por su parte, pasaron de representar el 32\% del total de los abastecimientos externos a menos del $1 \%$ al cabo del período analizado, al tiempo que se incrementó significativamente la ponderación de las compras de bienes primarios (del 9\% a cerca del 36\%).

Las capacidades tecnológicas de ambos países crecieron, si bien en diferentes momentos. Los senderos de incorporación tecnológica de la República de Corea y de China poseen ciertas similitudes y diferencias. En cuanto a las similitudes, su proceso de desarrollo económico (catching up) se sostuvo a través de la planificación estatal, pero de manera tardía, después del inicio de las reformas institucionales. Por ello, ambos países privilegiaron un primer ascenso hacia el cuadrante noroeste (véase el gráfico 3) y, una vez que consiguieron mayores capacidades productivas, siguieron una trayectoria hacia el noreste. Mientras que el Estado de la República de Corea apostó fuertemente por el aumento de sus capacidades tecnológicas a partir de la década de 1980 (Bekerman y Sirlin, 1996), en China se priorizó dicho proceso a partir de 2004 (Jaguaribe, 2015).

En cuanto al grado de éxito de su trayectoria de desempeño, desde el punto de vista de la canasta de participación creciente, en ambos países se logró consolidar una canasta exportadora que promueve el aumento de su participación en las exportaciones mundiales. Como se observa en el gráfico 4, ambas economías se sitúan actualmente a la derecha del nivel neutro. Sin embargo, en la década de 1960, se encontraban por debajo de dicho umbral. En la República de Corea, esta desfavorable posición inicial se revirtió tempranamente - en la década de 1970-, mientras que, en el caso chino, ello se logró en el transcurso de la década de 1980. Como se desprende de la información presentada, en la última década bajo estudio, los dos países vieron disminuir su índice de canasta de participación creciente, pese a lo cual se ubican muy por encima del nivel neutro ${ }^{12}$.

En tanto, el nivel de vida de ambas economías medido por el IDH se ha incrementado de modo sostenido durante período analizado (véase el gráfico 4): la República de Corea pasó de caracterizarse por registros muy bajos en comparación con otros países a ubicarse en la actualidad a la par de muchos países desarrollados. En concreto, la República de Corea sobrepasó la línea guía del IDH en la década de 1990 y se ubicó en el cuadrante noreste. Por otro lado, China parte en la década de 1960 de una situación peor que la de la República de Corea y, en la actualidad, presenta niveles de bienestar similares a los de países de ingreso medio, como México, pero por debajo de la línea guía del IDH, en el cuadrante sudeste.

\footnotetext{
12 Este fenómeno ocurrió principalmente por el aumento de los precios de los productos básicos.
} 


\section{Gráfico 4}

China y República de Corea: canasta de participación creciente e índice de desarrollo humano (trayectoria del desempeño) de dos países de industrialización reciente con capacidades tecnológicas recientes, 1963-2014

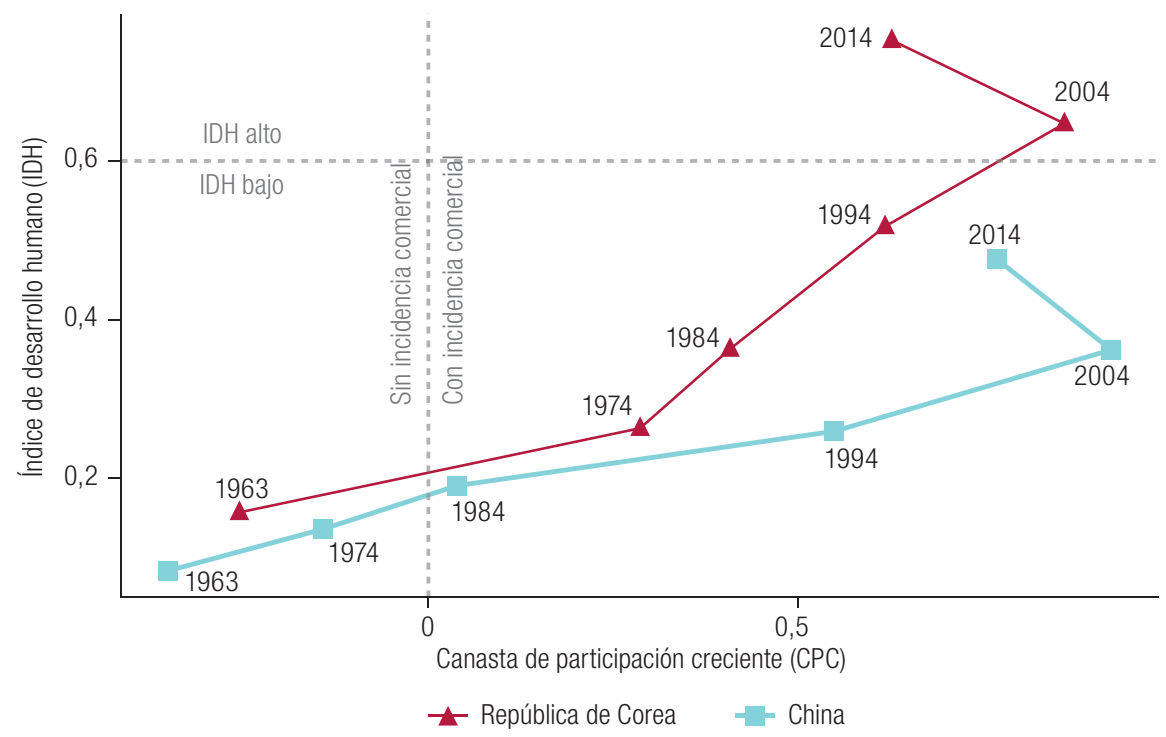

Fuente: Elaboración propia, sobre la base de Naciones Unidas, "UN Comtrade Database”, 2017 [base de datos en línea] https:// comtrade.un.org/; J. Bolt y J. van Zanden, "Maddison Project Database, version 2013", 2014 [online] http://www.ggdc. net/maddison/maddison-project/home.htm; R. Barro y J. Lee, "A new data set of educational attainment in the world, 1950-2010", Journal of Development Economics, vol. 104, septiembre, 2013; Banco Mundial, "Gasto en investigación y desarrollo (\% del PIB)", 2020 [base de datos en línea] https://datos.bancomundial.org/indicador/GB.XPD.RSDV.GD.ZS; Banco Mundial, "Población, total”, 2020 [base de datos en línea] https://datos.bancomundial.org/indicador/SP.POP. TOTL, y Programa de las Naciones Unidas para el Desarrollo (PNUD), Informe sobre Desarrollo Humano 2015: trabajo al servicio del desarrollo humano, Nueva York, 2015.

\section{b) Países con bajas capacidades tecnológicas}

Esta categoría incluye a México y la India. Se trata de dos países que realizaron reformas institucionales en la década de 1990 y, con sus especificidades, recorrieron un sendero basado en la liberalización del comercio y la movilidad de los capitales internacionales como elemento central de su desarrollo.

En el primer caso, el régimen de acumulación de industrialización dirigida por el Estado seguido durante la segunda mitad del siglo XX entró en un retroceso acelerado tras la crisis de la deuda mexicana de comienzos de la década de 1980. La salida de la crisis se articuló a través de un aumento del peso relativo de los actores foráneos, incluidos los organismos internacionales de crédito, así como de la búsqueda por atraer capitales estadounidenses. La primera reforma se inició en 1983 con la firma de acuerdos con los Estados Unidos y, en 1986, se produjo la adhesión del país al Acuerdo General sobre Aranceles Aduaneros y Comercio (GATT). Sin embargo, el aluvión de inversiones provenientes de los Estados Unidos no se dio hasta la suscripción del Tratado de Libre Comercio de América del Norte (TLCAN) en 1994 (Mariña y Cámara, 2015).

En este sentido, a diferencia de otros países con un importante peso económico en América Latina (sobre todo, la Argentina y el Brasil), México no ha centrado su inserción en la división internacional del trabajo en la explotación, el procesamiento y la comercialización de recursos naturales. Su participación en el mercado mundial se asemeja a la de los países de Centroamérica y el Caribe, en la medida en que su industrialización se lleva a cabo casi exclusivamente con el propósito de exportar bienes a los Estados Unidos, mediante el sistema de la maquila, fundamentalmente sobre la base de bajos costos 
salariales y una ostensible precarización laboral (Arceo, 2001). Uno de los ejes de las herramientas de política de fomento priorizadas para el desarrollo de la industria maquiladora es la creación de zonas con exenciones arancelarias de insumos industriales importados desde el exterior, con el fin de fomentar el libre comercio de las empresas extranjeras (Ordóñez y Bouchain, 2011).

La India, por su parte, se caracterizaba hasta comienzos de la década de 1990 por poseer una economía con cierta autarquía, organizada a través de una planificación centralizada inspirada en el socialismo soviético, y cuyo objetivo era alcanzar el desarrollo por medio de la industrialización (Kniivilä, 2007). En ese marco, el Estado controló la producción industrial a través de sus empresas y del establecimiento de las llamadas "licencias raj" 13, al tiempo que ejercía el monopolio del comercio exterior en los sectores estratégicos.

Este sistema, vigente durante varias décadas, comenzó a redefinirse en el transcurso de la década de 1980, cuando el Estado indio empezó a revisar su política económica con miras a otorgar un mayor grado de flexibilización comercial en procura de la modernización (Bhat, 2013). El paso a una economía con rasgos capitalistas se llevó a cabo a través de un retiro progresivo del Estado de su rol interventor; sin embargo, si bien se descartó la planificación centralizada, la planificación industrial no se abandonó y, en los hechos, viró hacia una planificación indicativa (Singh, 2008).

Como parte del viraje señalado, el Estado abandonó progresiva y gradualmente su injerencia en el comercio y la producción por medio de la desregulación y las privatizaciones, aunque el crecimiento de la economía en la India se venía acelerando con anterioridad a las políticas afines al libre comercio (Agarwal y Whalley, 2013). Esa dinámica fue liderada fundamentalmente por la industria y el sector de los servicios. En contrapartida, la agricultura perdió su protagonismo en las últimas décadas. Del lado de la demanda, este crecimiento fue traccionado por el aumento tanto de las exportaciones industriales como de la externalización de servicios. En tanto, los sectores de mayor dinamismo se encuentran vinculados al software y la industria farmacéutica.

En lo que se refiere a los senderos nacionales recorridos en las últimas décadas por ambos países, la información contenida en el gráfico 5 permite extraer varias conclusiones. Desde el punto de vista de las capacidades productivas reflejadas en el contenido tecnológico neto, México y la India presentan tanto similitudes como diferencias. Mientras que, en el caso de la India, la participación de sus exportaciones de alta tecnología se incrementó del 0,5\% en 1963 al 10,0\% en 2014, en el de México, este incremento fue de algo más del 1,0\% a cerca del 19,0\% en dicho período. La participación en las exportaciones de los productos primarios de México se redujo del 55,6\% en 1963 al 14,3\% en 2014, mientras que su participación de las exportaciones de tecnología media-alta aumentó del $4,6 \%$ al $41,6 \%$. Por su parte, la India incrementó la participación de las exportaciones de tecnología media-baja del 3\% en 1963 al 25,5\% en 2014. Del lado de las importaciones, la participación de los productos primarios de la India creció de manera significativa en las últimas décadas, pasando del 13,4\% en 1984 al 48,8\% en 2014. En tanto, a raíz del desarrollo del sistema maquilador, México redujo la participación de sus importaciones de tecnología media-alta e incrementó las de alta tecnología (del $52,5 \%$ al $36,5 \%$ y del $11,6 \%$ al $22 \%$ entre 1963 y 2014 , respectivamente).

\footnotetext{
${ }^{13}$ Dichas licencias permitían la participación del sector privado en las distintas ramas del sector industrial.
} 


\section{Gráfico 5}

India y México: contenido tecnológico neto de la balanza comercial y capacidades tecnológicas (sendero productivo) de dos países de industrialización reciente con bajas capacidades tecnológicas, 1963-2014

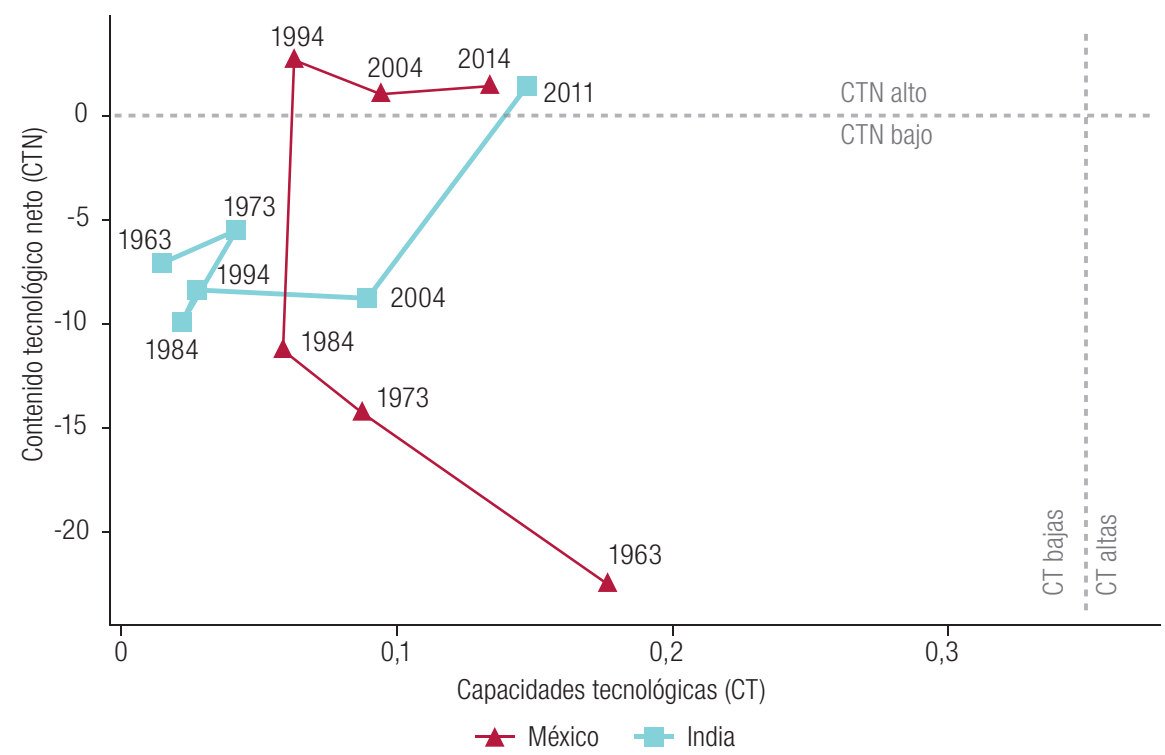

Fuente: Elaboración propia, sobre la base de Naciones Unidas, "UN Comtrade Database”, 2017 [base de datos en línea] https:// comtrade.un.org/; Oficina de Patentes y Marcas de los Estados Unidos, "Extended year set - patent counts by country, state, and year utility patents (December 2015)", 2020 [en línea] https://www.uspto.gov/web/offices/ac/ido/oeip/taf/ cst_uth.htm; Organización de Cooperación y Desarrollo Económicos (OCDE), "Gross domestic spending on R\&D", 2020 [base de datos en línea] https://data.oecd.org/rd/gross-domestic-spending-on-r-d.htm; Fundación Nacional de Ciencias, "Recent trends in U.S. R\&D performance", 2018 [base de datos en línea] https://www.nsf.gov/statistics/2018/ nsb20181/report/sections/research-and-development-u-s-trends-and-international-comparisons/recent-trends-in-u-sr-d-performance; Red de Indicadores de Ciencia y Tecnología (RICYT), "Comparativos", 2020 [base de datos en línea] http://www.ricyt.org/category/indicadores/; Organización de las Naciones Unidas para la Educación, la Ciencia y la Cultura (UNESCO), "Science, technology and innovation: Gross Domestic Expenditure on R\&D (GERD), GERD as a percentage of GDP, GERD per capita and GERD per researcher", 2020 [base de datos en línea] http://data.uis.unesco. org/index.aspx?queryid=74, y Banco Mundial, "Gasto en investigación y desarrollo (\% del PIB)", 2020 [base de datos en línea] https://datos.bancomundial.org/indicador/GB.XPD.RSDV.GD.ZS.

Este relativo avance productivo de ambas economías permitió su ascenso hacia el cuadrante noroeste del gráfico 5. Dicho ascenso les posibilitó ubicarse por encima del nivel neutro; es decir, actualmente son exportadoras netas de tecnología. Sin embargo, en 1963, ambas economías se encontraban muy por debajo de dicho nivel. México, en concreto, se encontraba por debajo de la India en lo que respecta a sus capacidades tecnoproductivas, pero, en la década de 1990, se convirtió en exportador neto de tecnología. Por su parte, la India logró tardíamente ubicarse por encima del nivel neutro, y no fue hasta la década de 2000 cuando pudo dar un salto relativo.

Por su carácter subordinado, ninguna de las dos economías logró incrementar sus capacidades tecnológicas, ya que no llevaron a cabo un proceso de mejora funcional mediante la adquisición de funciones nuevas o superiores en las cadenas de valor. En los años ochenta, el Estado de la India creó ZEE con el fin de beneficiar a las inversiones privadas, dotándolas de infraestructura. De esta forma, se consolidó una política de clústeres de relativo avance tecnológico. Asimismo, el dominio del inglés de la población, por el pasado colonial del país, y sus bajos niveles de remuneración de acuerdo con los estándares internacionales favorecieron la integración de la India en redes empresariales y académicas vinculadas a las potencias económicas, brindando un impulso al sector de los servicios (Delgado, 2015).

En lo que alude al grado de éxito de la trayectoria de su desempeño, tanto la India como México se encuentran en la actualidad en el cuadrante sudeste. El índice de la canasta de participación creciente 
de este último país es menor, pero relativamente similar al de los casos exitosos de industrialización (véase el gráfico 6). La India se encuentra muy por detrás de México; es decir, su canasta apenas garantiza el aumento de la participación mundial de sus exportaciones. Mientras que, en la década de 1970, México ya había logrado traspasar el umbral de neutralidad en lo que se refiere a la canasta de participación creciente, la India no logró traspasar dicho nivel hasta el nuevo milenio.

\section{Gráfico 6}

India y México: canasta de participación creciente e índice de desarrollo humano

(trayectoria del desempeño) de dos países de industrialización reciente con bajas capacidades tecnológicas, 1963-2014

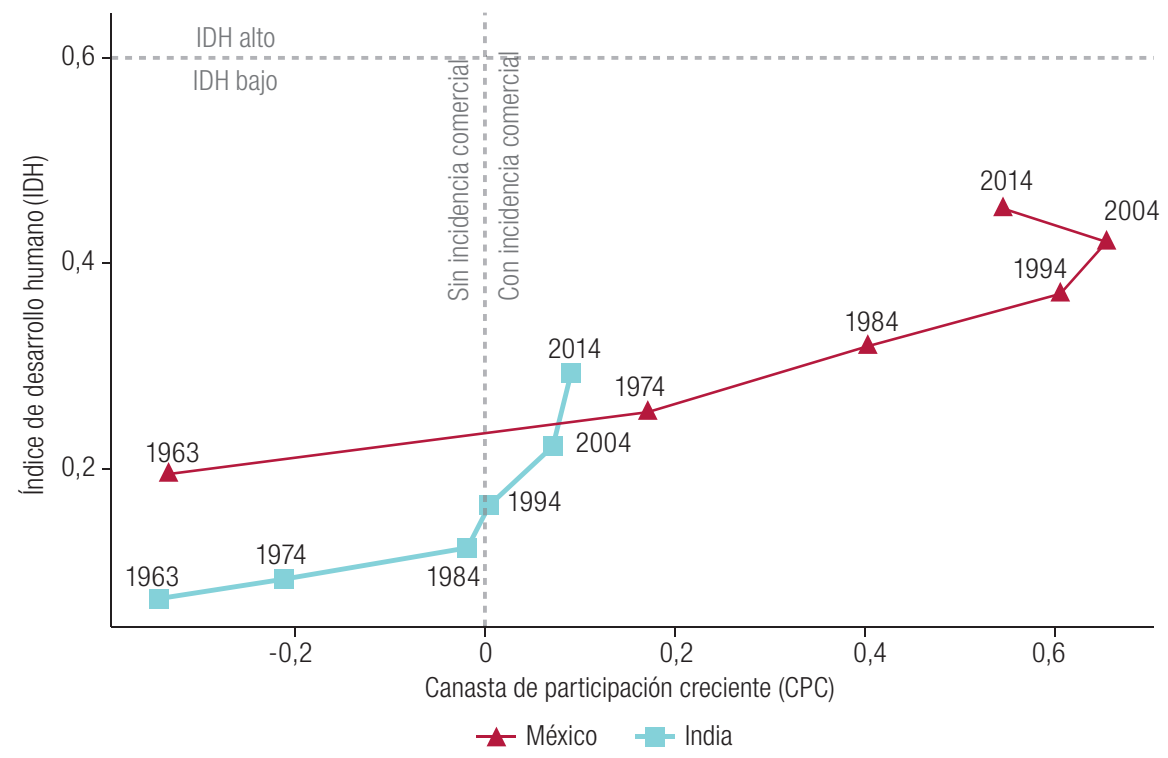

Fuente: Elaboración propia, sobre la base de Naciones Unidas, "UN Comtrade Database”, 2017 [base de datos en línea] https:// comtrade.un.org/; J. Bolt y J. van Zanden, "Maddison Project Database, version 2013", 2014 [online] http://www.ggdc. net/maddison/maddison-project/home.htm; R. Barro y J. Lee, "A new data set of educational attainment in the world, 1950-2010", Journal of Development Economics, vol. 104, septiembre, 2013; Banco Mundial, "Gasto en investigación y desarrollo (\% del PIB)", 2020 [base de datos en línea] https://datos.bancomundial.org/indicador/GB.XPD.RSDV.GD.ZS; Banco Mundial, "Población, total", 2020 [base de datos en línea] https://datos.bancomundial.org/indicador/SP.POP. TOTL, y Programa de las Naciones Unidas para el Desarrollo (PNUD), Informe sobre Desarrollo Humano 2015: trabajo al servicio del desarrollo humano, Nueva York, 2015.

En lo que respecta al nivel de vida medido por el IDH, la India no consiguió despegar hasta la década de 1990. En consecuencia, podría considerarse un país con un bajo nivel de calidad de vida. En tanto, en México se incrementó el nivel de vida a lo largo de toda la serie. Sin embargo, mientras que en la década de 1960 su IDH era apenas superior al de la República de Corea, actualmente se encuentra en niveles similares a los del Brasil; es decir, de una economía con una calidad de vida media. Ambas economías se encuentran distantes de la línea guía del IDH. 


\section{Países (re)primarizados}

\section{a) Países con capacidades tecnológicas}

En esta tipología se incluyen Australia y Noruega, que comparten el privilegio de ser los dos países con mejor calidad de vida del mundo, de acuerdo con el IDH elaborado por las Naciones Unidas (PNUD, 2015). Además, Noruega es el país de mayor capital natural per cápita y Australia, el séptimo (Hamilton y otros, 2009). En consecuencia, ambas economías se ubican en el cuadrante sudeste del sendero productivo (véase el gráfico 7).

\section{Gráfico 7}

Australia y Noruega: contenido tecnológico neto de la balanza comercial y capacidades tecnológicas (sendero productivo) de dos países primarizados con capacidades tecnológicas crecientes, 1963-2014

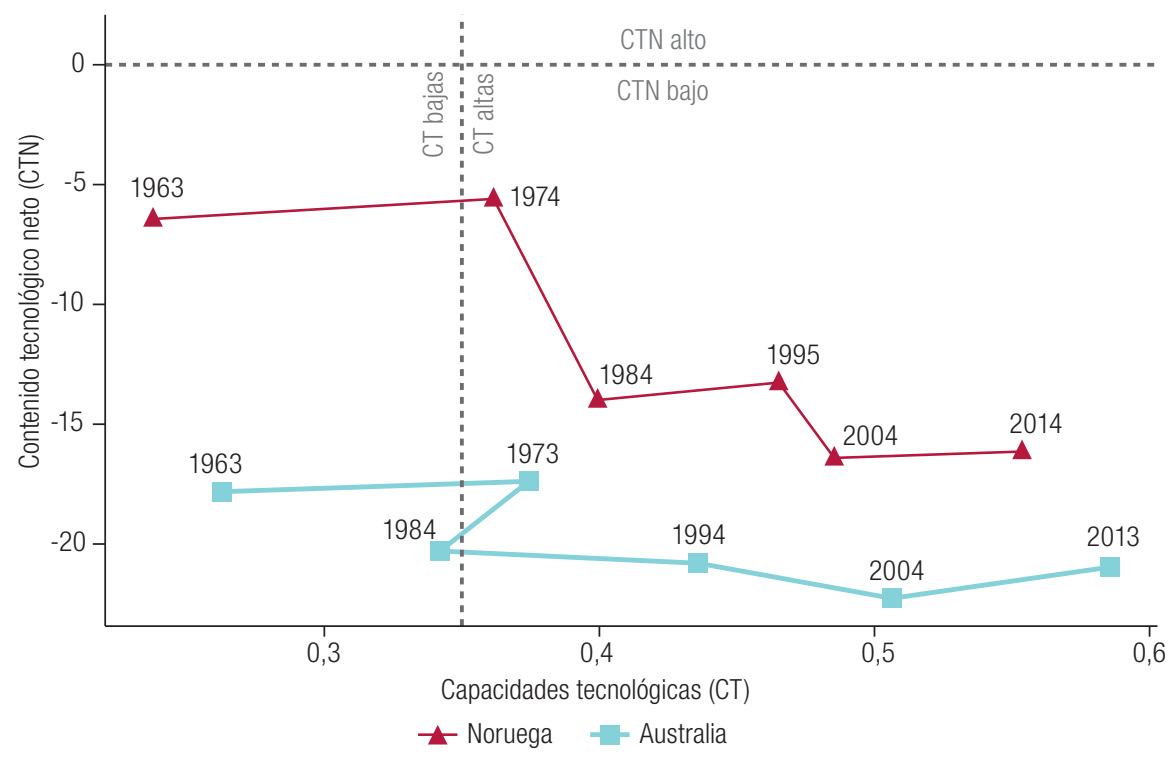

Fuente: Elaboración propia, sobre la base de Naciones Unidas, "UN Comtrade Database”, 2017 [base de datos en línea] https:// comtrade.un.org/; Oficina de Patentes y Marcas de los Estados Unidos, "Extended year set - patent counts by country, state, and year utility patents (December 2015)", 2020 [en línea] https://www.uspto.gov/web/offices/ac/ido/oeip/taf/ cst_utlh.htm; Organización de Cooperación y Desarrollo Económicos (OCDE), "Gross domestic spending on R\&D", 2020 [base de datos en línea] https://data.oecd.org/rd/gross-domestic-spending-on-r-d.htm; Fundación Nacional de Ciencias, "Recent trends in U.S. R\&D performance", 2018 [base de datos en línea] https://www.nsf.gov/statistics/2018/ nsb20181/report/sections/research-and-development-u-s-trends-and-international-comparisons/recent-trends-in-u-sr-d-performance; Red de Indicadores de Ciencia y Tecnología (RICYT), "Comparativos", 2020 [base de datos en línea] http://www.ricyt.org/category/indicadores/; Organización de las Naciones Unidas para la Educación, la Ciencia y la Cultura (UNESCO), "Science, technology and innovation: Gross Domestic Expenditure on R\&D (GERD), GERD as a percentage of GDP, GERD per capita and GERD per researcher", 2020 [base de datos en línea] http://data.uis.unesco. org/index.aspx?queryid=74, y Banco Mundial, "Gasto en investigación y desarrollo (\% del PIB)", 2020 [base de datos en línea] https://datos.bancomundial.org/indicador/GB.XPD.RSDV.GD.ZS.

El sendero privilegiado por Noruega se vincula al hallazgo de un enorme yacimiento de petróleo en su plataforma continental a fines de la década de 1960. Para entonces, Noruega ya era un país rico, productivamente diversificado, industrializado y exportador de bienes diferenciados. La participación de los productos primarios y de baja tecnología, que en 1962 representaban el 52\% de las exportaciones noruegas, en 1974 se había reducido al 40\%, mientras que, en el caso de los productos de medio y alto contenido tecnológico, esta se incrementó del $48 \%$ al $60 \%$ en el mismo período. Como se desprende del gráfico 7, hacia 1974, Noruega tenía un balance tecnológico comercial levemente negativo, bastante próximo al nivel neutro. En 1974, las exportaciones noruegas se dividían en un 13\% de productos primarios, un 
27\% de bienes de bajo contenido tecnológico, un 36\% de bienes de contenido tecnológico medio-bajo, un $20 \%$ de bienes de contenido tecnológico medio-alto y un $4 \%$ de bienes de contenido tecnológico alto. El mismo gráfico muestra que, unos años antes de 1974, Noruega incrementó rápidamente sus capacidades tecnológicas, en sintonía con el proceso descrito anteriormente.

Siguiendo a Schteingart (2017), la mayor parte de la explotación petrolera estuvo en sus comienzos vinculada al capital extranjero, que disponía de los conocimientos especializados necesarios, pero sometida a una fuerte regulación estatal que procuraba generar encadenamientos hacia atrás, apropiarse de la mayor parte de la renta petrolera y transferir tecnología a los actores locales. Se creó una empresa estatal que tenía como objetivo mantener el control nacional de la explotación petrolera y vincularla con el sistema científico-técnico. Para disminuir los efectos del síndrome holandés, Noruega creó un fondo estatal que se apropiaba de parte de las divisas generadas por la exportación de petróleo con el fin de afrontar la apreciación cambiaria.

Como consecuencia del auge petrolero, el contenido tecnológico neto del país escandinavo se redujo sensiblemente, pero continuaron incrementándose sus capacidades tecnológicas. En 2014, el $71 \%$ de las exportaciones noruegas correspondía a productos primarios y el resto se repartía en un $6 \%$ de bienes de bajo contenido tecnológico, un $13 \%$ de bienes de contenido tecnológico mediobajo, un $7 \%$ de bienes de contenido medio-alto y un $4 \%$ de bienes de contenido alto. Asimismo, el auge exportador posibilitó un crecimiento sin presencia de restricciones externas. En buena medida, el elevado PIB per cápita de Noruega se debe a la protección social integral brindada por un Estado de bienestar amplio desarrollado durante la segunda posguerra.

Por su parte, la economía australiana se estructura fundamentalmente en torno a la agricultura y la explotación minera, lo que le permitió desarrollar algunas industrias de tratamiento de metales y producción de bienes de capital para la minería, así como una variedad de servicios asociados. Su pertenencia al Commonwealth le otorgó prioridad a la hora de abastecer al Reino Unido de materias primas e incluso de algunos bienes industrializados - sobre todo armamento-, lo que fomentó la creación de institutos de investigación y la inversión en educación.

De los datos del gráfico 7, se desprende que, en 1963, el contenido tecnológico neto australiano era muy deficitario. En consecuencia, Australia se concentró en la explotación de recursos naturales y los encadenamientos vinculados a dichos recursos, sin buscar consolidar la expansión del sector industrial. A comienzos del período analizado, las exportaciones australianas de productos primarios y bienes de bajo contenido tecnológico alcanzaban el 92\% del total de exportaciones y, si bien registraron una tendencia decreciente hasta comienzos de la década de 1970, se mantuvieron siempre por encima del 60\%. Paralelamente, las exportaciones de alto contenido tecnológico, que en 1963 no llegaban al $1 \%$ del total, en la actualidad se aproximan al 4\%. En 2014, la canasta exportadora australiana estaba conformada por un $68 \%$ de productos primarios, un $10 \%$ de bienes de bajo contenido tecnológico, un 14\% de bienes de contenido tecnológico medio-bajo, un 5\% de contenido tecnológico medio-alto y un $3 \%$ de bienes contenido tecnológico alto. A lo largo de todo el período analizado, Australia profundizó su dependencia tecnológica, lo que se refleja en el déficit cada vez mayor de su contenido tecnológico neto.

Además, el Estado asumió un rol activo en la modernización de la infraestructura y en el gasto en educación e investigación. La inversión en infraestructura - en particular, los ferrocarriles - se llevó a cabo sobre todo a partir de iniciativas nacionales, en lugar de ser empresas europeas las que tomaran la delantera. La inversión en investigación y desarrollo, que ya era elevada en la década de 1970, se incrementó de manera sostenida a lo largo de todo el período, lo cual se refleja en su desplazamiento hacia la derecha en el gráfico 7.

Por razones geopolíticas y de especialización comercial, Australia logró sortear la restricción externa y experimentar un crecimiento sostenido a largo plazo. Su proximidad a Asia Oriental favoreció 
las exportaciones de sus materias primas a países de industrialización reciente, especialmente desde mediados del siglo pasado (Schteingart y Coatz, 2015). Como muestra el gráfico 8, el nivel del índice de canasta de participación creciente de Australia mejoró continuamente en el período analizado. Finalmente, como consecuencia de este desempeño económico y de un Estado que históricamente invirtió en protección social, particularmente en educación y salud, Australia se mantuvo durante todo el período entre los países con mayor IDH del mundo. En este sentido, tanto Noruega como Australia se encontraban en el cuadrante sudoeste de la trayectoria del desempeño durante la década de 1960. Sin embargo, en las últimas décadas, lograron alcanzar el cuadrante noreste.

\section{Gráfico 8}

Australia y Noruega: canasta de participación creciente e índice de desarrollo humano (trayectoria del desempeño) de dos países primarizados con capacidades crecientes, 1963-2014

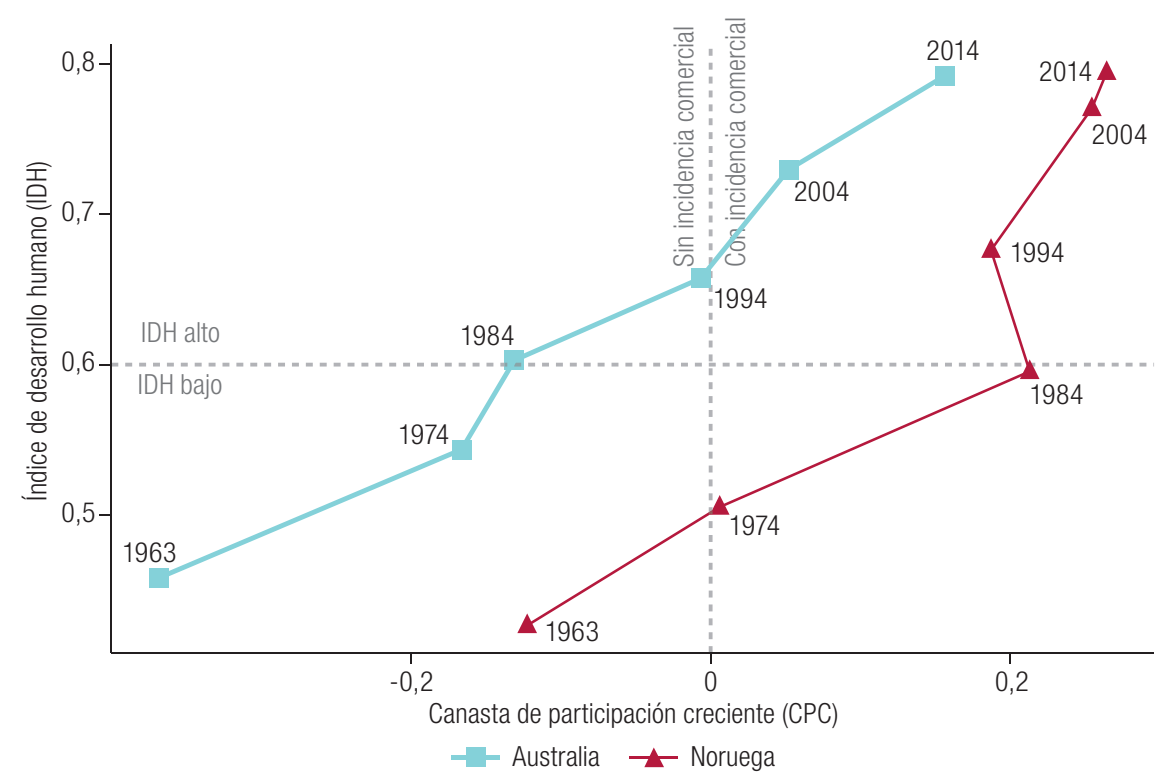

Fuente: Elaboración propia, sobre la base de Naciones Unidas, "UN Comtrade Database", 2017 [base de datos en línea] https:// comtrade.un.org/; J. Bolt y J. van Zanden, "Maddison Project Database, version 2013", 2014 [online] http://www.ggdc. net/maddison/maddison-project/home.htm; R. Barro y J. Lee, "A new data set of educational attainment in the world, 1950-2010", Journal of Development Economics, vol. 104, septiembre, 2013; Banco Mundial, "Gasto en investigación y desarrollo (\% del PIB)", 2020 [base de datos en línea] https://datos.bancomundial.org/indicador/GB.XPD.RSDV.GD.ZS; Banco Mundial, "Población, total", 2020 [base de datos en línea] https://datos.bancomundial.org/indicador/SP.POP. TOTL, y Programa de las Naciones Unidas para el Desarrollo (PNUD), Informe sobre Desarrollo Humano 2015: trabajo al servicio del desarrollo humano, Nueva York, 2015.

\section{b) Países con bajas capacidades tecnológicas}

En esta tipología se incluye a la Argentina, el Brasil y Chile, países que también siguieron una estrategia basada en la explotación, la producción y la comercialización de bienes basados en sus abundantes reservas de recursos naturales, pero que, a diferencia de Noruega y Australia, no generaron capacidades tecnológicas elevadas y alcanzaron un nivel de calidad de vida más bajo.

Estas economías se encuentran en el cuadrante sudoeste del sendero productivo y muy distantes de las líneas guías de neutralidad en lo que se refiere tanto al contenido tecnológico neto como a las capacidades tecnológicas (véase el gráfico 9). 


\section{Gráfico 9}

Argentina, Brasil y Chile: contenido tecnológico neto de la balanza comercial y capacidades tecnológicas (sendero productivo) de tres países reprimarizados con bajas capacidades tecnológicas, 1963-2014

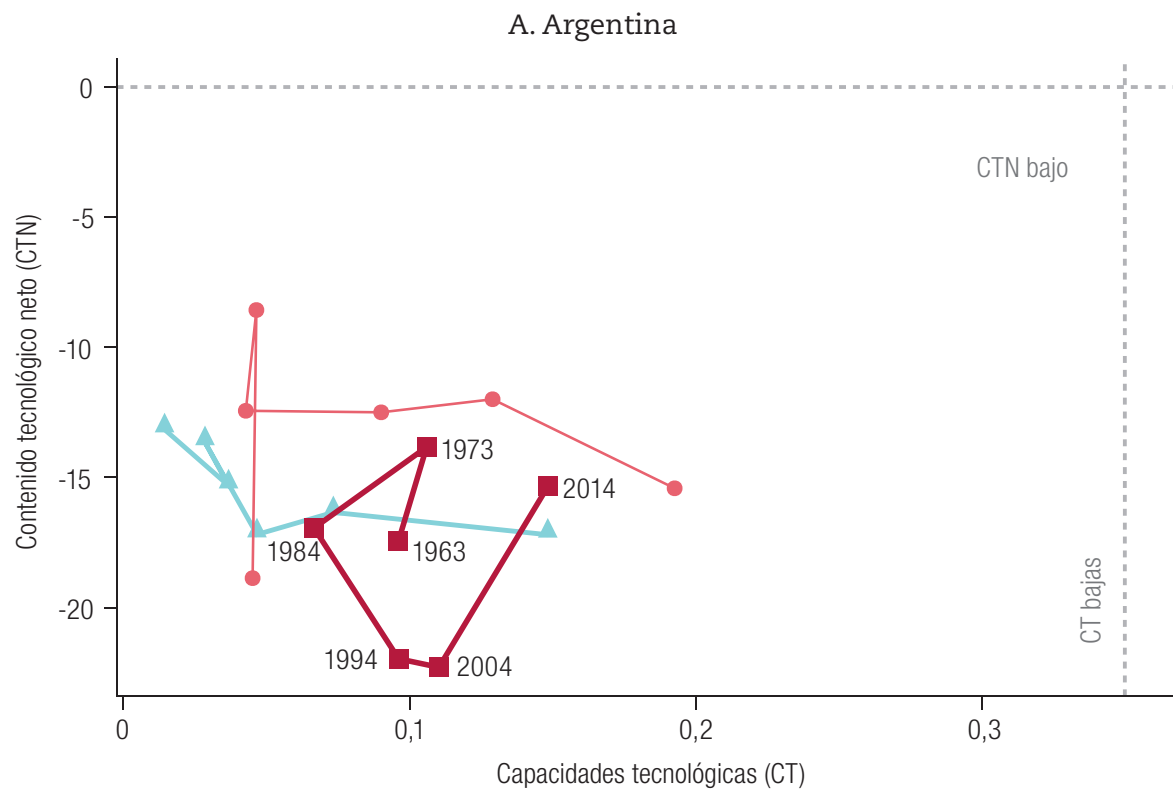

B. Brasil

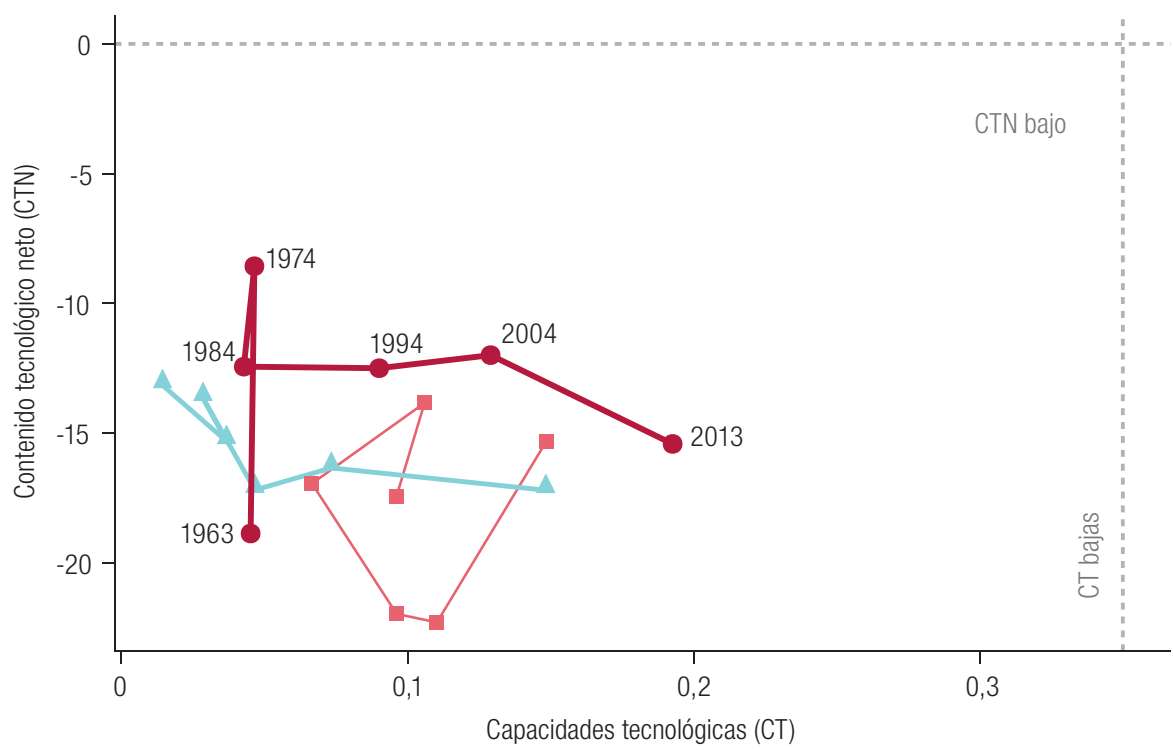


Gráfico 9 (conclusión)

\section{Chile}

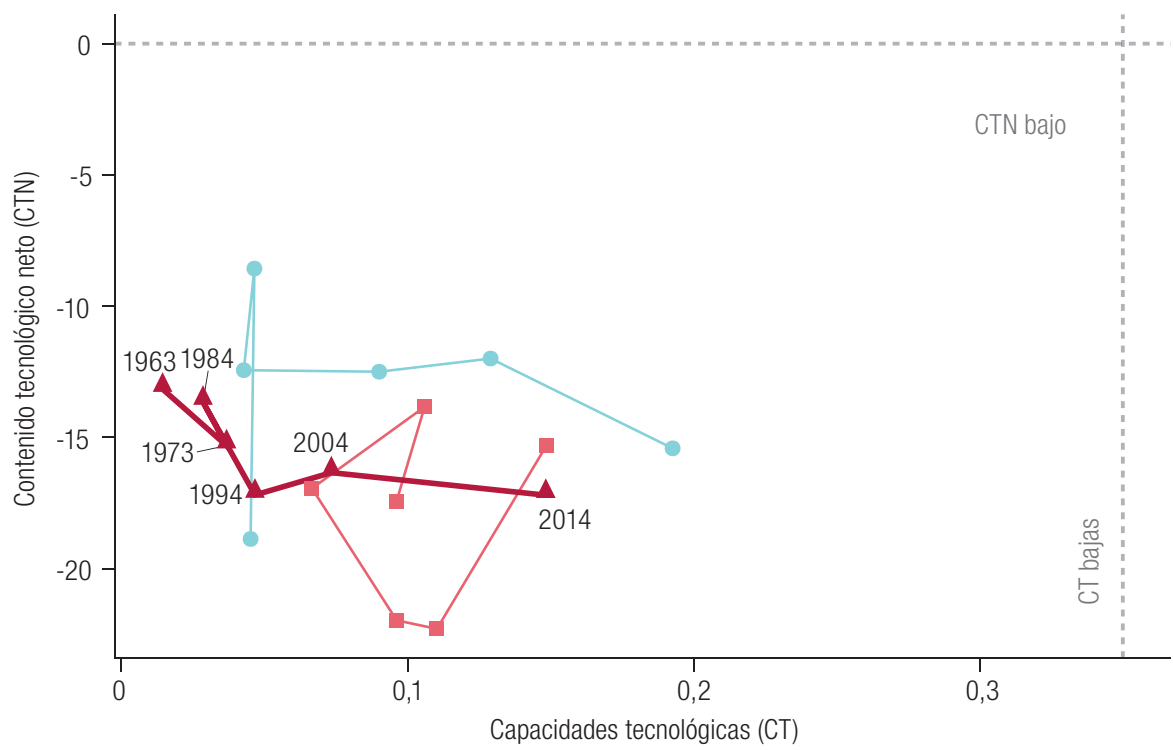

Fuente: Elaboración propia, sobre la base de Naciones Unidas, "UN Comtrade Database”, 2017 [base de datos en línea] https:// comtrade.un.org/; Oficina de Patentes y Marcas de los Estados Unidos, "Extended year set - patent counts by country, state, and year utility patents (December 2015)", 2020 [en línea] https://www.uspto.gov/web/offices/ac/ido/oeip/taf/ cst_utlh.htm; Organización de Cooperación y Desarrollo Económicos (OCDE), "Gross domestic spending on R\&D", 2020 [base de datos en línea] https://data.oecd.org/rd/gross-domestic-spending-on-r-d.htm; Fundación Nacional de Ciencias, "Recent trends in U.S. R\&D performance", 2018 [base de datos en línea] https://www.nsf.gov/statistics/2018/ nsb20181/report/sections/research-and-development-u-s-trends-and-international-comparisons/recent-trends-in-u-sr-d-performance; Red de Indicadores de Ciencia y Tecnología (RICYT), "Comparativos", 2020 [base de datos en línea] http://www.ricyt.org/category/indicadores/; Organización de las Naciones Unidas para la Educación, la Ciencia y la Cultura (UNESCO), "Science, technology and innovation: Gross Domestic Expenditure on R\&D (GERD), GERD as a percentage of GDP, GERD per capita and GERD per researcher", 2020 [base de datos en línea] http://data.uis.unesco. org/index.aspx?queryid=74, y Banco Mundial, "Gasto en investigación y desarrollo (\% del PIB)", 2020 [base de datos en línea] https://datos.bancomundial.org/indicador/GB.XPD.RSDV.GD.ZS.

En el comienzo del período analizado, la industrialización de la Argentina descansó fundamentalmente sobre ramas industriales livianas que dependían de tecnología e insumos industriales importados (Ferrer, 2004), por lo que el balance externo argentino continuó dependiendo de la exportación de productos primarios, como se manifiesta en el contenido tecnológico neto negativo y en las bajas capacidades tecnológicas de 1963. En ese año, el 43\% de la canasta exportadora argentina estaba conformada por productos primarios y el $52 \%$, por productos de bajo contenido tecnológico, mientras que las exportaciones de alto contenido tecnológico representaban apenas el 1\% y las de contenido tecnológico medio-alto, cerca del 2\%. Por otro lado, casi el 50\% de las importaciones eran productos de contenido tecnológico medio-alto.

En los años posteriores, maduraron las inversiones en industria pesada y bienes intermedios, que fueron impulsadas en un contexto de desarrollismo, en el que se recurrió decididamente a la inversión extranjera directa (Azpiazu, 1986). En consecuencia, se produjo una mejora relativa del contenido tecnológico neto, que, hacia 1975, se situó en el nivel más elevado de todo el período analizado. Además, la calidad de vida, medida por el IDH, mejoró notablemente (véase el gráfico 10). 


\section{Gráfico 10}

Argentina, Brasil y Chile: canasta de participación creciente e índice de desarrollo humano (trayectoria del desempeño) de tres países reprimarizados con bajas capacidades tecnológicas, 1963-2014

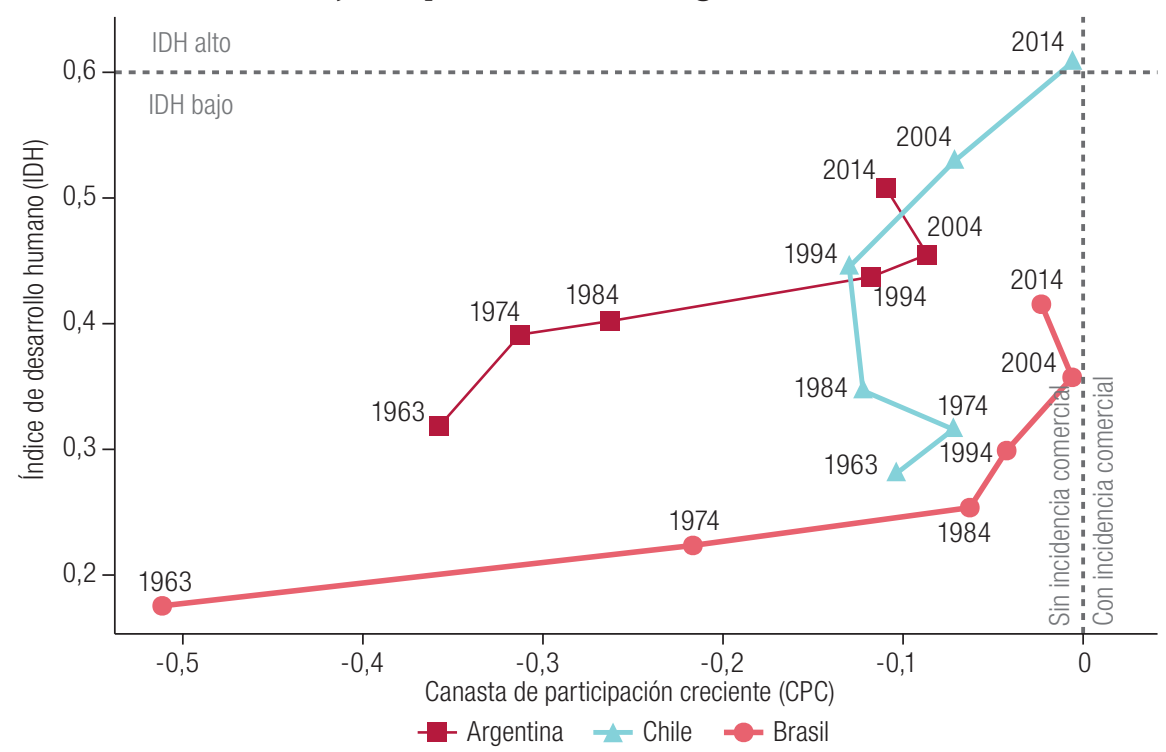

Fuente: Elaboración propia, sobre la base de Naciones Unidas, "UN Comtrade Database", 2017 [base de datos en línea] https:// comtrade.un.org/; J. Bolt y J. van Zanden, "Maddison Project Database, version 2013", 2014 [online] http://www.ggdc. net/maddison/maddison-project/home.htm; R. Barro y J. Lee, "A new data set of educational attainment in the world, 1950-2010", Journal of Development Economics, vol. 104, septiembre, 2013; Banco Mundial, "Gasto en investigación y desarrollo (\% del PIB)", 2020 [base de datos en línea] https://datos.bancomundial.org/indicador/GB.XPD.RSDV.GD.ZS; Banco Mundial, "Población, total", 2020 [base de datos en línea] https://datos.bancomundial.org/indicador/SP.POP. TOTL, y Programa de las Naciones Unidas para el Desarrollo (PNUD), Informe sobre Desarrollo Humano 2015: trabajo al servicio del desarrollo humano, Nueva York, 2015.

A partir de 1976, el golpe de Estado da inicio a un período neoliberal caracterizado por la apertura de la economía, que se articula con un cuadro de apreciación cambiaria, lo que produce una avalancha importadora de bienes industrializados, aumenta drásticamente el déficit de contenido tecnológico y destruye capacidades tecnológicas (Azpiazu y Schorr, 2010). Las importaciones que más rápidamente crecieron fueron las de medio-alto y alto contenido tecnológico. Por otra parte, el indicador de IDH se mantuvo estancado en este período. Terminada la dictadura militar, la única transformación relevante en la inserción comercial que se produjo durante la década siguiente fue el aumento de la participación de manufacturas basadas en productos primarios, agrícolas y energéticos, en detrimento de las materias primas sin procesar. Si bien se trata de productos de bajo contenido tecnológico, se observó una mejora del índice de canasta de participación creciente, ya que su participación en el comercio mundial creció más rápido que la participación de los productos primarios (véase el gráfico 10).

En la década de 1990, sobrevino una nueva oleada aperturista que volvió a aumentar el déficit del contenido tecnológico neto. Debido al aumento del desempleo, la distribución regresiva del ingreso y la profunda crisis económica de 2001, la calidad de vida mejoró muy poco en esta década.

A partir de 2004, se redujo el déficit del contenido tecnológico neto, que en 2014 alcanzó su nivel más bajo desde mediados de la década de 1970 - aunque sin llegar a los niveles anteriores a la dictadura-, pero esto ocurrió sin que se produjeran transformaciones relevantes en el perfil de especialización industrial (Schorr, 2018). Por el lado de la canasta importadora, destaca el aumento de la participación de los productos primarios, que llegó hasta el 15\%, en buena medida debido al incremento del déficit energético. Las capacidades tecnológicas mejoraron rápidamente gracias al crecimiento de la inversión pública y en ciencia y técnica, y el IDH también aumentó, impulsado por el crecimiento económico y la mejora de la distribución del ingreso. 
En el caso del Brasil, se observa una estrategia de inserción internacional similar a la argentina, basada en una industrialización liviana destinada al mercado interno (Furtado, 1962). En 1963, la canasta exportadora brasileña se componía de un $75 \%$ de productos primarios y un $17 \%$ de bienes de bajo contenido tecnológico. En los años posteriores, el Brasil atravesó un período de crecimiento acelerado y cambió sustancialmente su inserción comercial debido, fundamentalmente, a una política gubernamental que promovió la radicación de empresas extranjeras y la expansión de las filiales ya instaladas.

Hacia 1974, la canasta exportadora brasileña había cambiado de forma sustantiva, en buena medida debido al procesamiento de las materias primas para su exportación, lo que se refleja en el aumento de la participación de los bienes de bajo contenido tecnológico hasta el 40\%, en detrimento de los productos primarios, que retroceden al 34\%. Al mismo tiempo, las exportaciones de bienes de contenido tecnológico alto y medio-alto duplicaron con creces su participación en la canasta, alcanzando en conjunto el $21 \%$ del total. Así, el peso de los bienes de participación creciente en el comercio mundial aumentó en la canasta exportadora brasilera (véase el gráfico 9). No obstante, esta modificación en la inserción externa no fue acompañada de una mejora de las capacidades tecnológicas. La participación de la industria en el PIB se incrementó hasta llegar a más del 33\% en 1974 y continuó creciendo, hasta alcanzar su máximo histórico del 34\% en 1982.

En la década de 1980, comenzó un período de políticas neoliberales. En este período, la prioridad fue estabilizar los precios y mejorar la balanza de pagos para afrontar los pagos de la deuda externa mediante políticas ortodoxas de reducción de la demanda y revisión del rol del Estado. Las reformas se profundizaron en la década de 1990 e incluyeron, entre otras cosas, la apertura comercial, la liberalización del tipo de cambio, la reforma tributaria para reducir el gasto y las privatizaciones (Abreu, 2004).

El resultado de estas políticas fue un significativo retroceso del contenido tecnológico neto a comienzos de la década de 1980, que luego se estabilizó hasta mediados de la década de 1990, al mismo tiempo que se producía un rápido crecimiento de las capacidades tecnológicas. En dicho período, se produjo un aumento del peso de las importaciones con alto contenido tecnológico, que pasó del $11 \%$ en 1974 al 17\% en 1984.

Hacia la década de 1990, el superávit comercial se transformó en un abultado déficit, lo que comprometió el desarrollo industrial e incrementó la vulnerabilidad externa de la economía (Kupfer, Ferraz y Carvalho, 2009), que, en 1999, experimentó una crisis de cuenta corriente. En lo que respecta a la composición del comercio exterior, los bienes de alto contenido tecnológico continuaron ganando importancia en las importaciones - pasando del 15\% en 1994 al 20\% en 2003-, pero también en las exportaciones, en las que pasaron de representar cerca del 3\% en 1994 al 7\% en 2003.

La llegada del Partido de los Trabajadores al poder, en 2003, no revirtió los fundamentos del modelo económico neoliberal, aunque dio lugar un significativo período de rápido crecimiento económico y a una gran transformación de la política social que mejoró el nivel de vida de los habitantes del país (véase el gráfico 10). El aumento de los precios de las materias primas a partir de 2003, en conjunción con el marco de regulación económica neoliberal, condujo a la reprimarización de las exportaciones: los productos primarios, que representaban un 23\% de la canasta exportadora en 2003, constituían el 41\% de las exportaciones en 2014 (véase el gráfico 9). Sin embargo, las capacidades tecnológicas mejoraron notablemente, impulsadas por la inversión estatal.

En Chile, la etapa de sustitución forzada de importaciones continuó gracias a las políticas deliberadas de promoción industrial implementadas a partir de la asunción de distintos gobiernos progresistas durante la década de 1940, y se mantuvo hasta 1973. Hacia 1974, las exportaciones chilenas estaban conformadas por un $62,3 \%$ de bienes de tecnología media-baja (fundamentalmente, cobre) y un $20 \%$ de productos primarios. Esta especialización en la exportación de bienes de bajo contenido tecnológico se centró principalmente en bienes mineros (cobre) y pescado, cuya participación en el comercio mundial ha crecido en las últimas décadas (véase el gráfico 10). Esta es una diferencia importante con respecto 
a los patrones de especialización de la Argentina y el Brasil, que posteriormente posibilitaría a Chile crecer con mayor rapidez, aprovechando términos de intercambio mucho más favorables.

El golpe de Estado de 1973 supuso un giro drástico en las políticas económicas, que incluyó la apertura indiscriminada a las importaciones, la eliminación de controles a los precios, la liberalización del mercado financiero, la privatización de empresas públicas, la reducción del Estado, la represión sindical, una reforma tributaria regresiva y la liberalización del flujo de capitales internacionales (Ffrench-Davis, 2002). Al mismo tiempo, el Estado retiró parcialmente el financiamiento a la ciencia y la técnica, por lo que se produjo un retroceso en materia de capacidades tecnológicas (véase el gráfico 9).

La consecuencia fue una profundización del patrón de especialización comercial chileno. El ajuste de la demanda interna y la apertura importadora hicieron que la industria, que en 1973 representaba el 27\% del PIB, hacia 1981 hubiera reducido su participación al 22\%. La crisis externa de 1982 indujo al gobierno militar a introducir algunas modificaciones que atenuaron los efectos mencionados sobre la canasta importadora. Se realizaron sucesivas devaluaciones, se reestableció parte de la protección arancelaria y se otorgaron créditos y subsidios al sector privado.

La evolución del contenido tecnológico de las exportaciones fue ambigua en este período, a pesar de que hubo cambios en la composición de la canasta: aumentó la participación de los productos primarios, pero también de las manufacturas de contenido tecnológico medio-alto y bajo. En 1990, los productos primarios habían aumentado su participación al 31\% de la canasta exportadora, debido principalmente al mineral de cobre y las uvas, pero con una diversificación también hacia otros bienes como el salmón, las maderas y las frutas.

La vuelta a la democracia, en 1990, dio inicio a un período de crecimiento económico rápido y sostenido. Chile trató de evitar que su moneda se apreciara demasiado para asegurar el equilibrio externo y se benefició del elevado precio internacional del cobre, el ingreso de capitales atraídos por las altas tasas de interés y la renta de los recursos naturales (Ffrench-Davis, 2002). El crecimiento del PIB permitió mejorar la calidad de vida de la población, si bien persistieron niveles de desigualdad muy elevados. Chile superó la línea guía del IDH en la primera década del nuevo milenio. Sin embargo, su canasta de participación creciente se encuentra muy próxima al nivel neutro (véase el gráfico 10). La especialización comercial chilena se mantuvo dentro del patrón histórico y, en 2014, la participación en las exportaciones de los productos primarios (mineral de cobre) fue del 37\%; la de los bienes de bajo contenido tecnológico (papel, pescado congelado y vino), del 22\%, y la de los bienes de contenido tecnológico medio-bajo (cobre), del 34\%. No obstante, en la última década, Chile avanzó notablemente en la generación de capacidades tecnológicas gracias a la promoción estatal de la ciencia y la técnica.

\section{Conclusiones}

Los diferentes senderos nacionales de desarrollo que se han analizado permiten inferir la existencia de dos grandes vectores de especialización. Por un lado, se encuentran aquellos países de la periferia que desarrollaron ventajas dinámicas en industrias con tecnología de punta y, como consecuencia, pudieron escalar en las cadenas productivas hacia los eslabones de mayor valor agregado. Estos países lograron un buen desempeño en lo que se refiere a la calidad de vida promedio de sus habitantes y a su incidencia en el comercio internacional. Ejemplo de ello es la República de Corea. China, por su parte, es un país que se encuentra claramente en un proceso de transición para convertirse en una potencia capitalista.

Por otro lado, hallamos casos de especialización en ventajas comparativas, tanto en la exportación de productos ensamblados en el país con uso intensivo de mano de obra barata (como México y, en ciertos aspectos, China y la India, aunque este último a través de la externalización de servicios) 
como en la exportación de materias primas (por ejemplo, la Argentina, Australia, el Brasil, Chile y Noruega). Las naciones periféricas especializadas en el ensamble lograron una inserción comercial cada vez mayor, pero no aprovecharon dicha base industrial para escalar hacia los eslabones de mayor valor agregado, por lo que no alcanzaron niveles de vida elevados. Esto se debe a que los actores que se proyectan como hegemónicos no pretenden una transformación estructural de las diferentes matrices productivas, sino, fundamentalmente, aprovechar la reducción de los salarios a nivel internacional.

Noruega y Australia son países especializados en materias primas y con altos estándares de vida. Ambos países poseen recursos predominantemente mineros o hidrocarburíferos (a diferencia de países más sesgados hacia lo agrícola, como la Argentina y el Brasil). Además, en primer lugar, disponen de cuotas del mercado mundial considerables en lo que se refiere a la exportación de sus recursos naturales. En segundo lugar, cuentan con las mayores dotaciones de recursos per cápita, lo que - dada su reducida cantidad de habitantes, en comparación con los demás países analizadosles permite disponer de una estructura productiva especializada en recursos naturales que aglutina a gran parte de la población en su proyecto productivo. En tercer lugar, se trata de naciones que pudieron desarrollar cierta industria y servicios intensivos en conocimiento sobre la base de encadenamientos hacia atrás a partir de los recursos naturales. A pesar de insertarse por su especialización en recursos naturales, lograron conformar una canasta exportadora que les confirió una incidencia cada vez mayor en el comercio mundial.

Los datos presentados permiten afirmar que, si bien los países que tuvieron un desempeño exitoso siguieron diferentes senderos de especialización, muchos de ellos coinciden en haber utilizado instrumentos similares para que el camino escogido fuera virtuoso. En particular, y a pesar de los matices, se observa la existencia de una profunda y persistente intervención estatal orientada a modificar la composición de la estructura productiva para favorecer a determinados sectores seleccionados de la industria y los servicios y a reducir la brecha tecnológica que los separa de los países más avanzados. Para ello, se utilizaron incentivos al capital, subordinados al cumplimiento de estrictas metas de desempeño tecnológico, productivo o comercial. De esta manera, en los casos exitosos, el Estado desarrolló en distintos niveles una planificación de carácter indicativo más o menos intensa.

En cuanto a los actores empresarios protagonistas del proceso de desarrollo, en algunos casos, el Estado impulsó la consolidación de grandes conglomerados nacionales (por ejemplo, los chaebol de la República de Corea) y, en otros, asumió el rol de empresario, mediante la creación de empresas públicas (es el caso de países tan distintos como China y Noruega). La inversión extranjera directa fue promovida intensamente en algunos países; por lo general, sujeta a controles y exigencias de desempeño (por ejemplo, en materia de transferencia tecnológica).

Del análisis de los distintos senderos nacionales que se reseñaron en este trabajo, pueden extraerse algunas lecciones importantes, si bien siempre hay que tener en cuenta que no existe un sendero ideal y que cada caso de desarrollo es irrepetible por un sinfín de razones. Por ello, no se pretende llegar a una conclusión determinante sobre el sendero que debería seguir la Argentina, sino recuperar algunos aspectos de otras experiencias nacionales, a fin de reflexionar sobre los alcances y las limitaciones que se presentan en el difícil y complejo (pero necesario) tránsito hacia el desarrollo.

Respecto al trayecto recorrido en los casos de industrialización reciente, resulta difícil pensar que la Argentina pueda seguir un derrotero similar, dado que no dispone de la mano de obra abundante y barata de la que se valieron esos países para desarrollar los eslabones basados en el ensamble de partes y piezas para su posterior exportación.

No obstante, tanto la experiencia de los países de industrialización reciente como de muchos países centrales deja lecciones importantes para pensar sobre el desarrollo argentino. Cabe destacar que todos los casos de industrialización reciente priorizaron un primer ascenso hacia la región noroeste 
del sendero productivo, pero solo los exitosos se dirigieron posteriormente hacia el noreste. A pesar de sus diferencias, en estos ámbitos nacionales se llevó a cabo un cambio en la composición sectorial a partir de una selección de industrias por parte del Estado, quien, además, desempeñó un papel fundamental en su impulso.

En este punto, las corporaciones transnacionales podrían ser un obstáculo, dado que insertan a la Argentina en los segmentos de menor contenido tecnológico en las cadenas de valor globales, impidiendo su avance a nichos más complejos. Por lo tanto, la Argentina podría encontrar nichos de tecnología alta o media en los que sería posible desarrollar capacidades y exportar al menos a escala regional. Al mismo tiempo, también pueden recuperarse algunos instrumentos de política, sin olvidar que el desempeño de algunos países se basó en la disponibilidad de mano de obra barata.

El sendero seguido por los países exitosos basados en recursos naturales tampoco podría considerarse un camino unívoco para la Argentina. A diferencia de estos, la Argentina dispone de recursos agrarios (no mineros o petroleros) y una dotación por habitante muy inferior, por lo que su potencial sería insuficiente para relajar el estrangulamiento externo. Sin embargo, a diferencia de Australia y Noruega, el país no aprovecha suficientemente la demanda generada por los sectores productores de materias primas para desarrollar proveedores locales en sectores clave. Como consecuencia, muchos de los insumos de mayor contenido tecnológico son importados. En los países exitosos, se logró desarrollar estos proveedores locales a partir de políticas estatales activas y sostenidas, y establecer tributos sobre la renta de los recursos naturales con el fin de financiar las líneas de fomento.

\section{Bibliografía}

Abreu, M. (2004), "The Brazilian economy, 1980-1994", Texto para Discussão, № 492, Río de Janeiro, Pontificia Universidad Católica de Río de Janeiro, enero.

Agarwal, M. y J. Whalley (2013), "The 1991 reforms, Indian economic growth, and social progress", NBER Working Paper, № 19024, Cambridge, Oficina Nacional de Investigaciones Económicas (NBER), mayo.

Amsden, A. (1993), "Trade policy and economic performance in South Korea", Trade and Growth: New Dilemmas in Trade Policy, M. Agosin y D. Tussie (eds.), Londres, The Macmillian Press Ltd.

(1992), Corea, un proceso exitoso de industrialización tardía, Bogotá, Grupo Editorial Norma.

Araujo, R. y G. Lima (2007), "A structural economic dynamics approach to balance-of-payments-constrained growth", Cambridge Journal of Economics, vol. 31, № 5.

Arceo, E. (2001), "El ALCA: un nuevo pacto colonial", Instituto de Estudios y Formación de la Central de Trabajadores de la Argentina/Instituto de Estudios sobre Estado y Participación [en línea] http://www. bibliotecacta.org.ar/bases/pdf/IDE00132.pdf.

Azpiazu, D. (1986), "La promoción industrial en la Argentina, 1973-1983: efectos e implicancias estructurales", Documento de Trabajo, № 19 (INT-0455), Buenos Aires, Comisión Económica para América Latina y el Caribe (CEPAL).

Azpiazu, D. y M. Schorr (2010), "La industria argentina en la posconvertibilidad: reactivación y legados del neoliberalismo", Problemas del Desarrollo: Revista Latinoamericana de Economía, vol. 41, № 161, Ciudad de México, Universidad Nacional Autónoma de México (UNAM).

Barro, R. y J. Lee (2013), "A new data set of educational attainment in the world, 1950-2010", Journal of Development Economics, vol. 104, septiembre.

Bekerman, M. y P. Sirlin (1996), "La estrategia exportadora de Corea del Sur", Comercio Exterior, vol. 46, № 6.

Bértola, L., M. Hernández y S. Siniscalchi (2012), "Un índice histórico de desarrollo humano de América Latina y algunos países de otras regiones: metodología, fuentes y bases de datos", Documento de Trabajo, № 28, Montevideo, Universidad de la República (UDELAR).

Bhat, T. (2013), "Growth and structural changes in Indian industry", Working Paper, № 2013/02, Nueva Delhi, Institute for Studies in Industrial Development, febrero.

Bolt, J. y J. van Zanden (2014), "Maddison Project Database, version 2013" [en línea] http://www.ggdc.net/ maddison/maddison-project/home.htm. 
Cassini L., G. García Zanotti y M. Schorr (2017), "Los caminos al desarrollo: trayectorias nacionales divergentes en tiempos de globalización", Documentos de Investigación Social, № 29, San Martín, Instituto de Altos Estudios Sociales (IDAES).

Castaldi, C. (2009), "The relative weight of manufacturing and services in Europe: an innovation perspective", Technological Forecasting and Social Change, vol. 76, № 6, julio.

CEPAL (Comisión Económica para América Latina y el Caribe) (2007), "Progreso técnico y cambio estructural en América Latina", Documentos de Proyectos (LC/W.136), Santiago, octubre.

Chang, D. (2009), "The mystified state: explaining the state in the economic miracle", Capitalist Development in Korea: Labour, Capital and the Myth of the Developmental State, Abingdon, Routledge.

Cimoli, M., G. Porcile y S. Rovira (2010), "Structural change and the BOP-constraint: why did Latin America fail to converge?", Cambridge Journal of Economics, vol. 34, № 2, marzo.

Cimoli, M. y otros (2005), "Cambio estructural, heterogeneidad productiva y tecnología en América Latina", Heterogeneidad estructural, asimetrías tecnológicas y crecimiento en América Latina, Documentos de Proyectos (LCM.35), M. Cimoli (ed.), Santiago, Comisión Económica para América Latina y el Caribe (CEPAL), noviembre.

Dalum, B., K. Laursen y B. Verspagen (1999), "Does specialization matter for growth?", Industrial and Corporate Change, vol. 8, No 2.

Delgado, I. (2015), "Política industrial na China, na Índia e no Brasil: legados, dilemas de coordenação e perspectivas", Texto para Discussão, № 2059, Brasilia, Instituto de Investigación Económica Aplicada (IPEA), marzo.

De Vries, G. y otros (2011), "Deconstructing the BRICs: structural transformation and aggregate productivity growth", GGDC Working Papers, vol. GD 121, Groningen, Universidad de Groningen.

Dosi, G., K. Pavitt y L. Soete (1993), La economía del cambio técnico y el comercio internacional, Ciencia, Tecnología y Desarrollo Económico, Ciudad de México, Consejo Nacional de Ciencia y Tecnología (CONACYT).

Ferrer, A. (2004), La economía argentina: desde sus orígenes hasta principios del siglo XXI, Buenos Aires, Fondo de Cultura Económica.

Ffrench-Davis, R. (2002), "Chile, entre el neoliberalismo y el crecimiento con equidad", Revista de Economía Política, vol. 22, № 4.

Furtado, C. (1962), Formación económica del Brasil, Ciudad de México, Fondo de Cultura Económica.

Gereffi, G. (2010), "China y México en la economía global: trayectorias de desarrollo divergentes en una era de crisis económica", Foro Internacional, vol. 50, № 3-4 (201-202), Ciudad de México, El Colegio de México (COLMEX).

Hamilton, K. y otros (2009), ¿Dónde está la riqueza de las naciones?: medir el capital para el siglo XXI, Washington, D.C., Banco Mundial.

Hausmann, R., J. Hwang y D. Rodrik (2007), "What you export matters", Journal of Economic Growth, vol. 12, № 1, marzo.

Hikino, T. y A. Amsden (1995), "La industrialización tardía en perspectiva histórica", Desarrollo Económico, vol. 35, No 137, abril-junio.

Jaguaribe, A. (2015), "Capacidades estatais comparadas: China e a reforma do sistema nacional de inovações", Texto para Discussão, № 2085, Brasilia, Instituto de Investigación Económica Aplicada (IPEA), abril.

Kniivilä, M. (2007), "Industrial development and economic growth: implications for poverty reduction and income inequality", Industrial Development for the 21st Century: Sustainable Development Perspectives, Nueva York, Naciones Unidas.

Kupfer, D., J. Ferraz y L. Carvalho (2009), "50 años en 50: el largo y sinuoso camino del desarrollo industrial de Brasil", Boletín Informativo Techint, № 330.

Lavopa, A. (2015), "Structural transformation and economic development: can development traps be avoided?", tesis de doctorado, Maastricht, Universidad de Maastricht.

Lugones, G., D. Suárez y N. Le Clech (2007), "Conducta innovativa y desempeño empresarial”, Documentos de Trabajo, N 33, Buenos Aires, Centro de Estudios sobre Ciencia, Desarrollo y Educación Superior.

Lugones, G., D. Suárez y S. Gregorini (2007), "La innovación como fórmula para mejoras competitivas compatibles con incrementos salariales: evidencias en el caso argentino", Documentos de Trabajo, № 36, Buenos Aires, Centro de Estudios sobre Ciencia, Desarrollo y Educación Superior.

Marín, A. (2016), "Las industrias de recursos naturales como plataforma para el desarrollo de América Latina", Nuevos enfoques para el desarrollo productivo: Estado, sustentabilidad y política industrial, Ciudad de México, Friedrich Ebert Stiftung. 
Mariña, A. y S. Cámara (2015), "Las especificidades de la crisis mundial en México: una historia de integración subordinada a la globalización neoliberal", Crisis neoliberal y alternativas de izquierda en América Latina Il: México, J. Valenzuela Feijóo y otros (coords.), Ciudad de México, El Barzón ANACC.

Moncaut, N. y D. Vázquez (2017), "El sendero de desarrollo chino y sus particularidades: incidencia e implicancias para los países sudamericanos", Realidad Económica, №305, Buenos Aires, Instituto Argentino para el Desarrollo Económico (IADE).

Ordóñez, S. y R. Bouchain (2011), "Cómo se ubica México en el capitalismo del conocimiento y la nueva división internacional del trabajo", Capitalismo del conocimiento e industria de servicios de telecomunicaciones en México, Ciudad de México, Universidad Nacional Autónoma de México (UNAM)/ Instituto de Investigaciones Económicas.

Pérez, C. (2010), "Dinamismo tecnológico e inclusión social en América Latina: una estrategia de desarrollo productivo basada en los recursos naturales", Revista CEPAL, № 100 (LC/G.2442-P), Santiago, Comisión Económica para América Latina y el Caribe (CEPAL).

(2001), "Cambio tecnológico y oportunidades de desarrollo como blanco móvil", Documentos de Proyectos, Estudios e Investigaciones (INT-2188), Santiago, Comisión Económica para América Latina y el Caribe (CEPAL).

PNUD (Programa de las Naciones Unidas para el Desarrollo) (2015), Informe sobre Desarrollo Humano 2015: trabajo al servicio del desarrollo humano, Nueva York.

Rodrik, D. (2006), "What's so special about China's exports?", China \& World Economy, vol. 14, № 5.

Schorr, M. (coord.) (2018), Entre la década ganada y la década perdida: la Argentina kirchnerista, ensayos de economía política, Buenos Aires, Batalla de Ideas.

Schteingart, D. (2017), "Especialización productiva, capacidades tecnológicas y desarrollo económico: trayectorias nacionales comparadas y análisis del caso noruego desde mediados del siglo XX", tesis de doctorado, Universidad Nacional de San Martín (UNSAM).

(2014), "Estructura productivo-tecnológica, inserción internacional y desarrollo económico: hacia una tipología de senderos nacionales", tesis de maestría, Universidad Nacional de San Martín (UNSAM).

Schteingart, D. y D. Coatz (2015), “¿Qué modelo de desarrollo para la Argentina?”, Boletín Informativo Techint, $N^{\circ} 349$.

Singh, A. (2008), "The past, present and future of industrial policy in India: adapting to the changing domestic and international environment", Working Paper, N ${ }^{\circ}$ 376, Cambridge, Centre for Business Research, diciembre.

Thirlwall, A. y J. McCombie (2004), Essays on balance of payments constrained growth, Londres, Routledge.

Verspagen, B. (2000), "Growth and structural change: trends, patterns and policy options", Research Memorandum, $N^{\circ} 15$, Maastricht, Universidad de Maastricht.

Wang, L. y A. Szirmai (2008), "Productivity growth and structural change in Chinese manufacturing, 1980-2002", Industrial and Corporate Change, vol. 17, № 4, agosto. 